\title{
Indicateurs de laïcité dans deux démocraties contemporaines
}

Analyse comparative entre le Mexique et l'Argentine

Indicators of secularism in contemporary democracies: a comparative analysis

between Mexico and Argentina

Indicadores de la laicidad en las democracias contemporáneas: análisis

comparativo entre México y Argentina

Roberto Blancarte et Juan Cruz Esquivel

\section{(2) OpenEdition}

Journals

Édition électronique

URL : http://journals.openedition.org/assr/29336

DOI : $10.4000 /$ assr.29336

ISSN : $1777-5825$

Éditeur

Éditions de l'EHESS

Édition imprimée

Date de publication : 1 mars 2017

Pagination : 191-236

ISSN : 0335-5985

Référence électronique

Roberto Blancarte et Juan Cruz Esquivel, « Indicateurs de laïcité dans deux démocraties contemporaines », Archives de sciences sociales des religions [En ligne], 177 | 2017, mis en ligne le 01 mars 2019, consulté le 05 janvier 2021. URL : http://journals.openedition.org/assr/29336 ; DOI : https://doi.org/10.4000/assr.29336 
Roberto Blancarte

Juan Cruz Esquivel

\section{Indicateurs de laïcité dans deux démocraties contemporaines} Analyse comparative entre le Mexique et l'Argentine

Les prises de position et les débats récents autour de la ou des laïcités nous ont amenés à un constat fondamental: on ne peut réduire les alternatives réelles de la plupart des sociétés contemporaines aux seules deux catégories d'État confessionnel et d'État laïc ou séculier. La mondialisation, les migrations, l'expansion des codes libertaires et la non-discrimination, la pluralisation des croyances et la prise de conscience de notre diversité en tant qu'êtres humains, ont donné lieu à la constitution de régimes plutôt laïques, quel que soit le nom qu'ils se soient octroyés. Faisant référence à la vie publique, Émile Poulat affirme: "Celle-ci a longtemps été commandée par le principe de catholicité; elle est désormais soumise au principe de laïcité ", (Poulat, 2003 : 113). Si cet auteur fait explicitement référence au cas français, il est clair que le postulat dépasse le catholicisme et peut être appliqué à de nombreux autres régimes du monde occidental, voire au-delà du christianisme, à de nombreuses autres nations non occidentales. Malgré la montée des fondamentalismes religieux, les régimes qui organisent formellement la vie publique du monde obéissent de moins en moins à des critères religieux. Les régimes de chrétienté, de catholicité, les régimes islamiques, bouddhistes ou fondés sur une autre religion sont de plus en plus rares. Le problème n'est donc plus de savoir quels sont les pays laïques et ceux qui ne le sont pas, mais plutôt de comprendre dans quelle mesure et jusqu'à quel point un pays est laïque. Cette grande question en amène plusieurs autres: existe-t-il une seule façon de comprendre et d'exercer la laïcité ? Comment pouvons-nous affirmer qu'un État est laïque? Y a-t-il une laïcité meilleure que l'autre? Quels critères nous permettraient d'en faire l'évaluation?

Nous nous proposons ici de mettre à l'épreuve un outil méthodologique qui offre une série d'indicateurs de laïcité, afin de parvenir non seulement à identifier des niveaux de laïcisation étatique, mais également le profil adopté par la laïcité dans chaque État. Cet outil prétend analyser la laïcité dans différents contextes politiques et culturels. Une première comparaison portera sur 
le Mexique et l'Argentine, deux pays qui ont emprunté des voies différentes quant aux rapports entre politique et religion.

L'analyse repose d'une part sur des considérations d'ordre juridique qui permettent de détecter les indices religieux présents dans la législation et, d'autre part, sur une approche politique et institutionnelle qui examine les contenus des politiques publiques, les instances de médiation politiques et religieuses impliquées dans l'élaboration et la formulation de celles-ci, et qui identifie les niveaux de confession présents dans la culture politique hégémonique.

\section{De la discussion théorique à la construction méthodologique}

Nous partons du postulat qu'il n'y a pas une seule manière de comprendre ou de concevoir la laïcité. "Ce qu'on est venu à appeler globalement la laïcité est une notion complexe qui renvoie à une réalité proliférante. Dire la laïcité, comme on l'entend souvent, c'est faire dans l'abstraction et la simplification; c'est parler entre initiés qui s'accordent sur un certain nombre de choix fondamentaux, ou entre adversaires qui se combattent sur ces choix » (Poulat, 2003 : 11). Or l'affaire a dépassé le cercle des initiés; elle s'est massifiée et a pénétré l'opinion publique, non seulement en France, mais encore dans des pays comme le Mexique, la Turquie ou l'Uruguay. La laïcité fait partie des débats centraux dans de nombreux pays, que ceux-ci portent sur sa conception générale, ou certains de ses aspects particuliers comme l'avortement, l'éducation, les libertés, etc.

Nombreux sont ceux qui ont cru que la question pouvait être résolue, ou du moins élucidée, en ajoutant des adjectifs. On obtient ainsi une vaste panoplie de laïcités: les tenants de l'antagonisme ont clamé une laïcité ouverte (ce qui supposait l'existence d'une laïcité fermée); d'autres ont clamé une nouvelle laïcité, ce qui impliquait le dépassement d'autres laïcités, même si celle-ci courait le risque de vieillir rapidement au regard d'autres laïcités toujours plus actuelles; le Saint-Siège parle d'une laïcité saine (ce qui implique l'existence d'une laïcité malade ou nocive); falsifiée ou lepénisée, face à une version compréhensive ou intégratrice; républicaine, bien qu'il puisse y avoir une laïcité monarchique et constitutionnelle. Les possibilités sont aussi diverses que les adjectifs possibles: laïcité identitaire, subsidiaire, intelligente, jacobine, catholique, défigurée, nocive, avancée, fictive, authentique, soumise, menacée, réelle, etc. Face à l'inévitable prolifération d'épithètes, il ne nous reste plus qu'à revenir au fondamental: la laïcité n'a pas besoins d'adjectifs, de qualificatifs ou de déterminants, que ceux-ci soient explicatifs ou relationnels. "On parle beaucoup aujourd'hui d'une lä̈cité nouvelle, oubliant trop souvent qu'à son corps défendant, elle n'a cessé de se renouveler pour des raisons parfois contradictoires. On parle aussi de laïcité ouverte, mais que serait une laïcité refermée sur elle-même sinon la négation ou la falsification de ce qu'elle entend être: un principe d'organisation publique d'une coexistence acceptable et acceptée par tous?" (Poulat, 2003, 21). La laïcité est finalement soumise à une redéfinition 
permanente, au fur et à mesure des changements et des époques. Il faut donc accepter que le concept doive être interprété et approprié au contexte culturel dans lequel il prend corps.

Tenter un inventaire des laïcités est une autre approche possible. Il y a ici deux points de vue possibles : ceux qui prétendent interpréter la laïcité à partir d'un modèle unique, générateur essentiel dans le temps et dans l'espace, diffusé ensuite dans d'autres lieux, sous une forme plus ou moins pervertie par rapport à un modèle original et authentique. Pour certains, «l'exception française » et le modèle de l'Hexagone constitueraient l'archétype qui fait office de norme. D’autres pensent que la laïcité est un phénomène aux multiples origines qui se nourrit d'expériences diverses, et que celles-ci ont conformé différents modèles qui se sont alimentés les uns les autres. Nous en avons un exemple clair dans le cas des laïcités nord-américaine et mexicaine, qui sont le produit de plusieurs influences (tout spécialement à travers les révolutions anglaise et française), mais qui a leur tour ont d'une certaine manière influencé la laïcité européenne. Cette dernière approche implique non pas une mais plusieurs laïcités, façonnées au gré des différentes expériences nationales, voire plusieurs laïcités qui coexistent au sein d'une même réalité nationale.

Mentionnons à ce propos l'effort réalisé par Jean Baubérot et Micheline Milot, qui ont récemment proposé une caractérisation fondée sur des types idéaux, à partir de plusieurs expériences. Ils ont essayé de montrer que la liberté de conscience et l'égalité prennent des formes différentes selon les modalités d'autonomie du politique à l'égard du religieux:

1) Laïcité séparatiste où l'idée de séparation (entre religion et politique, État et Église, public et privé) peut être perçue comme une fin en soi;

2) Laïcité anticléricale, spécifique des pays dans lesquels les religions ou les Églises ont dominé la vie sociale et qui surgit par réaction militante contre le pouvoir des états religieux;

3) Laïcité autoritaire, qui s'accompagne généralement d'une ingérence de l'État dans les affaires internes des religions organisées, ou d'atteintes à la liberté d'expression et de manifestation;

4) Laïcité de foi civique, où l'on finit implicitement par exiger que les minorités religieuses partagent les valeurs de la majorité religieuse qui sont intégrées à la culture;

5) Laïcité de reconnaissance, fondée sur l'autorité morale de chaque personne (fondamentale pour la notion de libre conscience) et qui privilégie la justice sociale et le respect des décisions individuelles;

6) Laïcité de collaboration, dans laquelle l'État se considère comme autonome par rapport aux autorités religieuses, mais qui sollicite leur collaboration dans plusieurs domaines (Baubérot et Milot, 2011, 87-120).

Comme on peut le constater, et comme le signalent Baubérot et Milot, aucun de ces types idéaux n'est le reflet d'une réalité spécifique et aucune expérience historique ne répond à un modèle unique. Dans la pratique, les pays partagent plusieurs traits de ces types-idéaux de laïcité. Le cas français, par exemple, contient des éléments des cinq premiers types de laïcité, et la proposition de 
Sarkozy était d'y ajouter le sixième, celui de la collaboration. Les États-Unis d'Amérique présentent un mélange de laïcité de séparation, de foi civique et de reconnaissance, mais celle-ci n'est ni anticléricale ni autoritaire. Le cas mexicain offre clairement des traits de laïcité séparatiste, anticléricale, voire autoritaire, surtout à certains moments de son histoire, mais également de foi civique et de reconnaissance, tout particulièrement au cours des dernières décennies; toutefois, elle s'oppose clairement à toute forme de collaboration, en raison $\mathrm{du}$ "principe historique de séparation » inscrit dans la constitution.

Il ne s'agit donc pas de suivre des modèles nationaux de laïcité, parce qu'il n'en existe pas de forme pure. Il y a dans la pratique plusieurs conceptions de la laïcité, qui naviguent entre la normativité juridique, la jurisprudence, la pratique publique et la culture politique. On peut trouver plusieurs formes de laïcité, complémentaires ou contradictoires dans un même pays, voire sous une même législation. En témoigne l'article 24 de la constitution mexicaine, récemment réformé (juillet 2013). À la suite d'une négociation, l'article 24 combine plusieurs conceptions de la laïcité. Les premières lignes de l'article, dans lesquelles sont reconnus le droit à la liberté de convictions éthiques, la liberté de conscience et de religion, pourraient suggérer une laïcité de reconnaissance; la seconde partie de ce même paragraphe, dans lequel il est stipulé que personne ne pourra utiliser la liberté religieuse à des fins politiques, évoque plutôt une laïcité anticléricale. Les paragraphes suivants, dans lesquels il est stipulé que «le Congrès ne pourra dicter des lois qui établissent ou interdisent une religion quelconque» et que les manifestations de culte public devront généralement être célébrées dans les temples, s’inscrivent dans une laïcité de séparation. Ainsi, plutôt que de chercher à définir des types idéaux ou des qualificatifs de laïcité, il serait peut-être plus utile pour l'analyse d'identifier les particularités des divers modèles de laïcité et éventuellement d'en mesurer les degrés dans les différents domaines de la laïcité de l'État.

C'est à partir du constat précédent qu'a surgi la possibilité de construire un indice fiable, susceptible de répertorier les composantes des processus juridiques, politiques et culturels, et qui, au-delà de simples perceptions, permettrait une comparaison utile à grande échelle. Depuis quelques années, plusieurs spécialistes latino-américains se sont efforcés de développer une série d'indicateurs dans trois domaines spécifiques, liés à la laïcité des institutions: 1) la normativité juridique 2) les politiques publiques 3) la culture politique. Entre 2009 et 2010, nous avons réalisé un exercice comparatif, centré uniquement sur la première des trois sections, soit la normativité juridique générale. Ce premier exercice partiel nous a permis de formuler quelques interrogations méthodologiques qui furent recueillies dans le document initial. Nous signalions dans ce document combien les débats sur la laïcité tendaient non seulement à l'eurocentrisme, mais ils étaient également confus, localistes et donc de faible portée. Nous l'attribuions à l'époque à l'absence d'une compréhension universelle du concept, et donc à une définition peu claire du phénomène. De là nos efforts pour parvenir à une définition globale. Nous avons fait référence à la «Déclaration universelle sur la laïcité au XXI ${ }^{\mathrm{e}}$ siècle » 
et aux principales composantes de cette définition: 1) la liberté de conscience 2) autonomie du politique par rapport au religieux et 3) garantie d'égalité et de non-discrimination. Ainsi, nous avons défini l'État laïque comme «un instrument juridique et politique au service des libertés dans une société qui se reconnaît comme plurielle et diverse » et la laïcité comme "un régime social de coexistence, dont les institutions politiques ne sont plus légitimées par des éléments sacrés ou religieux, mais en premier lieu par la souveraineté populaire».

Dans cet article, nous affirmons que la proposition, bien que fondée sur une définition de la laïcité qui prétend être universelle, a été élaborée par des spécialistes d'une région spécifique du monde, l'Amérique latine, marquée par une approche particulière de ce que doivent être un état laïque et la laïcité. Nous y signalons également que l'indice est lui-même le produit de cette approche de la laïcité, et que dans ce sens il s'inscrit dans un débat plus vaste sur la définition et la mise en pratique de celle-ci. Nous prétendons cependant éviter, dans la mesure du possible, des confrontations inutiles sur un sujet en soi difficile et polémique. Il est clair, toutefois, que l'indice reflète une définition de la laïcité qui pénalise aussi bien le confessionnalisme que l'ingérence de l'État dans les affaires des associations religieuses ou la sacralisation des symboles civiques. Il est clair également que l'indice proposé tend à une définition de la laïcité qui repose sur le principe de la séparation, de la défense des droits sexuels et reproductifs, droits qui symbolisent d'une certaine manière les nouvelles frontières des droits humains. Bref, nous reconnaissons qu'aucun indicateur ne peut être objectif, puisqu'il dépend d'une perspective culturelle et d'une définition qui considère la diversité des droits et le pluralisme comme des éléments fondamentaux et essentiels de nos sociétés. C'est dans ce sens que notre proposition de construire un indice mondial de laïcité doit être appréhendée.

\section{Les indicateurs de laïcité}

La définition opérationnelle d'un terme complexe, condensée dans une série d'indicateurs, ne présuppose pas un outil neutre. Comme nous l'avons affirmé précédemment, elle renvoie forcément à une définition conceptuelle déterminée. La sélection des indicateurs qui permettront de contraster empiriquement ce terme complexe repose sur des bases théoriques. De là l'explicitation des principes que nous considérons comme constitutifs de la laïcité et qui sont à la base de la construction de notre outil méthodologique. Même si celui-ci est constamment soumis à la révision et la reformulation, il prétend être l'instrument qui analyse l'agir de l'État à travers ses liens avec le religieux dans différents contextes historiques, politiques et culturels.

L'exercice proposé pour aborder les types et les niveaux de laïcité des États commence par identifier les différents plans où celle-ci s'avère opérationnalisée et d'y analyser ses différentes variantes en fonction des dimensions d'analyse proposées. Nous pourrions ainsi explorer la modalité assumée par 
la laïcité au sein de la normativité juridique, des politiques publiques et dans le domaine de la culture politique. Pleinement conscients que l'analyse n'est pas réductible à de seules approches juridiques, nous contemplons des facteurs socioculturels pour parvenir à une approche plus précise de l'objet d'étude. Les trois dimensions considérées sont à leur tour divisées en sous-dimensions et une multiplicité d'indicateurs, dont l'ensemble renvoie à une définition théorique du concept de laïcité.

La sélection des trois dimensions développées obéit à la considération des trois niveaux de la vie sociale historiquement reflétés par les points d'intersection, de conflit et de négociation entre le politique et le religieux.

78 indicateurs au total ont été élaborés : 20 pour la dimension «normativité juridique», 44 pour les «politiques publiques» et 14 pour la «culture politique ». Chacune des dimensions possède un facteur de pondération particulier: $30 \%$ dans le cas de normativité juridique; $45 \%$ pour les politiques publiques et $25 \%$ pour la culture politique. Étant donné que les politiques publiques établissent le terrain d'application des politiques de l'État et montrent la diversité des domaines de gestion (éducation, sexualité, bioéthique, développement social, sciences, culte religieux, moyens de communication, etc.), on a préféré leur octroyer un poids spécifique plus grand par rapport aux autres dimensions d'analyse. On a appliqué également un facteur de pondération distinct pour les sous-dimensions et les indicateurs des trois dimensions analytiques, selon l'importance octroyée à chacun d'entre eux. Dans tous les cas, le chiffre 0 représente le niveau le plus bas de laïcité, alors que le 4 exprime le niveau le plus élevé.

Mentionnons par ailleurs qu'il s'agit d'une analyse qui porte sur les États nationaux dans des conjonctures historiques déterminées, et que l'année 2014 marquera la limite temporelle de référence. La dynamique politique et culturelle des sociétés conduit à des transformations et des redéfinitions au sein des législations, des politiques publiques, voire de la propre culture politique, qui exigeront dans le futur de nouvelles données pour identifier les niveaux de laïcisation dans chaque formation politique particulière.

\section{La normativité juridique}

Nous avons considéré trois sous-dimensions et leurs indicateurs respectifs pour rendre compte du cadre légal: fondement et caractère de l'État; relations État/institutions religieuses; garantie des droits fondamentaux.

Comme le montre le tableau 1, un État qui détient une religion officielle obtient la note la plus basse en termes de laïcité, de même qu'un État qui se proclame athée. Toute imposition par l'État d'une doctrine particulière, qu'elle soit religieuse ou philosophique, s'oppose à la pleine garantie de la liberté de conscience, droit humain universel. C'est dans ce sens que tout État confessionnel ou tout État qui prétend diffuser dans la société un cadre idéologique homogénéisateur et totalitaire constituent l'antithèse d'un État laïque. 
La laïcité repose explicitement sur un principe d'autonomie entre le politique et le religieux. À ce stade de l'analyse, il est donc pertinent d'affirmer que l'existence d'accords passés avec les institutions religieuses, le financement du culte, la présence de symboles religieux durant les cérémonies gouvernementales, entre autres, compromettent la souveraineté de l'État, et par conséquent, sa laïcité. Parallèlement, tout État qui se mêle des affaires confessionnelles (désignation des responsables, autorisation de distribution des documents religieux, influence sur les ordres ou les communautés) ou qui impose des restrictions au prosélytisme religieux, porte non seulement atteinte à la liberté de culte, mais encore ne respecte pas intégralement les principes constitutifs de la laïcité.

Précisons dans ce sens que l'indicateur "financement gouvernemental à des fins religieuses» inclut et différentie la contribution directe de l'État, la non-imposition des institutions religieuses et les apports fiscaux individuels.

Dans la rubrique «type d'enregistrement du culte», deux aspects sont considérés simultanément pour la construction des catégories de l'indicateur: au cas où celui-ci existerait, on évalue d'une part son caractère obligatoire, et d'autre part si l'obligation concerne toutes les institutions religieuses ou seulement certaines d'entre elles. Au Mexique, par exemple, toutes les associations religieuses peuvent le faire, mais aucune d'entre elles n'y est obligée, pas plus qu'aucune n'en est exemptée. En Argentine, par contre, l'enregistrement du culte précède toute activité, mais elle ne concerne que les institutions religieuses non catholiques, dans la mesure où l'Église catholique est la seule à avoir une personnalité publique, au même titre que tout organisme gouvernemental.

La catégorisation et l'évaluation de l'indicateur "participation des agents religieux dans les hôpitaux publics, les prisons et les forces armées » témoignent également de la conceptualisation de la laïcité qui est faite ici. Aussi bien la présence officielle des agents religieux que leur interdiction sont considérées comme contraires à la laïcité. Dans le premier cas, parce que le prosélytisme des agents religieux est institué par l'État. Dans le second, parce qu'il contredit le principe de liberté de conscience dans la mesure où il prive le citoyen du droit à demander personnellement la présence d'un spécialiste religieux.

Nous présentons dans les pages suivantes le tableau complet de la dimension «normativité juridique», avec ses sous-dimensions respectives, ses indicateurs et ses catégories, tableau dans lequel on précise les facteurs de pondération correspondants. 
Tableau 1 : dimension “normativité juridique ”

\begin{tabular}{|c|c|c|}
\hline Dimension & Sous-dimension & Indicateurs \\
\hline \multirow[t]{5}{*}{$\begin{array}{l}\text { Normativité } \\
\text { juridique } \\
(30 \%)\end{array}$} & $\begin{array}{l}\text { a) Fondement et } \\
\text { caractère de l'État } \\
(20 \%)\end{array}$ & $\begin{array}{l}\text { I) Type d'invocation à l'origine de la légitimité } \\
\text { étatique } \\
(25 \%) \\
\text { - Dieu/autre figure religieuse } \\
0 \\
\text { - Dieu/Souveraineté populaire } \\
1 \\
\text { - Aucune } \\
2 \\
\text { - Souveraineté populaire } \\
4\end{array}$ \\
\hline & & $\begin{array}{l}\text { II) Définition de l'État en matière religieuse } \\
(50 \%) \\
\text { - Religion officielle/État athée } \\
0 \\
\text { - Religion privilégiée ou nationale } \\
1 \\
\text { - Référence au principe de séparation } \\
3 \\
\text { - Laïque } \\
4\end{array}$ \\
\hline & & $\begin{array}{l}\text { III) Référence à des éléments religieux parmi les } \\
\text { symboles de la patrie } \\
(25 \%) \\
- \text { Oui } \\
0 \\
- \text { Non } \\
4\end{array}$ \\
\hline & $\begin{array}{l}\text { b) Relation État/ } \\
\text { Institutions religieuses } \\
(40 \%)\end{array}$ & $\begin{array}{l}\text { I) Existence d'un Concordat/Accords avec les } \\
\text { institutions religieuses } \\
(20 \%) \\
\text { - Oui } \\
0 \\
\text { - Non } \\
4\end{array}$ \\
\hline & & $\begin{array}{l}\text { II) Financement gouvernemental à des fins } \\
\text { religieuses } \\
(20 \%) \\
\text { - Contribution directe de l'État } \\
0 \\
\text { - Exemptions fiscales pour les institutions religieuses } \\
1 \\
\text { - Apports fiscaux par décision individuelle } \\
2 \\
\text { - Sans financement } \\
4\end{array}$ \\
\hline
\end{tabular}




\begin{tabular}{|c|c|c|}
\hline Dimension & Sous-dimension & Indicateurs \\
\hline & & $\begin{array}{l}\text { III) Type de procuration/personnalité juridique des } \\
\text { institutions religieuses } \\
(10 \%) \\
- \text { Publique } \\
0 \\
- \text { Sans personnalité } \\
1 \\
- \text { Privée } \\
4\end{array}$ \\
\hline & & $\begin{array}{l}\text { IV) Type d'enregistrement du culte } \\
(10 \%) \\
- \text { Obligatoire différentié } \\
0 \\
- \text { Optatif différentié } \\
1 \\
- \text { Obligatoire égalitaire } \\
2 \\
\text { - Optatif égalitaire } \\
3 \\
\text { - Sans enregistrement } \\
4\end{array}$ \\
\hline & & $\begin{array}{l}\text { V) Existence de tribunaux religieux exclusifs interdi- } \\
\text { sant l'exercice de la législation nationale } \\
(5 \%) \\
- \text { Oui } \\
0 \\
- \text { Non } \\
4\end{array}$ \\
\hline & & $\begin{array}{l}\text { VI) Existence de cérémonies religieuses dans les } \\
\text { célébrations officielles } \\
(10 \%) \\
- \text { Prévu légalement } \\
0 \\
- \text { Non prévu légalement } \\
2 \\
- \text { Interdit légalement } \\
4\end{array}$ \\
\hline & & $\begin{array}{l}\text { VII) Existence de registres civils en matière de } \\
\text { naissances, mariages, et décès } \\
(10 \%) \\
- \text { Non } \\
0 \\
- \text { Reconnaissance par le civil des registres religieux } \\
1 \\
- \text { Oui } \\
4\end{array}$ \\
\hline & & $\begin{array}{l}\text { VIII) Ingérence de l'État dans les affaires intérieures } \\
\text { des institutions religieuses } \\
(10 \%) \\
- \text { Oui } \\
0 \\
- \text { Non } \\
4\end{array}$ \\
\hline
\end{tabular}




\begin{tabular}{|c|c|c|}
\hline Dimension & Sous-dimension & Indicateurs \\
\hline & & $\begin{array}{l}\text { IX) Restrictions légales au droit à la conversion ou } \\
\text { au prosélytisme religieux } \\
(5 \%) \\
- \text { Oui } \\
0 \\
- \text { Non } \\
4\end{array}$ \\
\hline & $\begin{array}{l}\text { c) Garantie des droits } \\
\text { fondamentaux } \\
(40 \%)\end{array}$ & $\begin{array}{l}\text { I) Reconnaissance de la liberté de conscience et/ou } \\
\text { de croyance et de culte } \\
(12,5 \%) \\
- \text { Non } \\
0 \\
- \text { Oui } \\
4\end{array}$ \\
\hline & & $\begin{array}{l}\text { II) Discrimination pour raison de croyances à l'accès } \\
\text { à des postes publics } \\
(12,5 \%) \\
- \text { Non } \\
0 \\
- \text { Oui } \\
4\end{array}$ \\
\hline & & $\begin{array}{l}\text { III) Reconnaissance de la diversité comme valeur } \\
(12,5 \%) \\
- \text { Non } \\
0 \\
- \text { Oui en termes d'anti-discrimination } \\
2 \\
\text { - Non en termes de réaffirmation } \\
4\end{array}$ \\
\hline & & $\begin{array}{l}\text { IV) Ratification du protocole facultatif de la } \\
\text { CEDAW (Convention on the Élimination of All } \\
\text { Forms of Discrimination Against Women) } \\
(12,5 \%) \\
- \text { Non } \\
0 \\
- \text { Oui } \\
4\end{array}$ \\
\hline & & $\begin{array}{l}\text { V) Respect de l'autonomie reproductive } \\
(12,5 \%) \\
- \text { Non } \\
0 \\
- \text { Oui } \\
4\end{array}$ \\
\hline & & $\begin{array}{l}\text { VI) Établissement de l'éducation laïque } \\
(12,5 \%) \\
- \text { Non } \\
0 \\
- \text { Oui } \\
4\end{array}$ \\
\hline
\end{tabular}




\begin{tabular}{|c|c|c|}
\hline Dimension & Sous-dimension & Indicateurs \\
\hline & & $\begin{array}{l}\text { VII) Objection de conscience dans les services publics } \\
(12,5 \%) \\
- \text { En aucun cas } \\
0 \\
- \text { Dans tous les cas } \\
1 \\
- \text { Seulement dans les cas de respect du droit des tiers } \\
4\end{array}$ \\
\hline & & $\begin{array}{l}\text { VIII) Pénalisation de l'homosexualité } \\
(12,5 \%) \\
- \text { Oui } \\
0 \\
- \text { Non } \\
4\end{array}$ \\
\hline
\end{tabular}

\section{Les politiques publiques}

L'élaboration et la formulation des politiques publiques reposent sur des contenus axiologiques qui nous permettent d'évaluer et de nuancer leur fond laïc ou confessionnel. La bioéthique, les droits sexuels et reproductifs, l'éducation, le genre, le développement démographique sont des domaines de la gestion publique, dont l'analyse permet d'appréhender les modalités de la laïcité de l’État.

Afin de pouvoir appliquer notre outil d'évaluation, on ne considérera pas ici la mise en pratique des politiques publiques, mais leurs instances de formulation. Sans méconnaître les possibilités de déphasage entre les deux instances, analyser l'application des politiques publiques suppose d'étendre l'analyse aux provinces et aux municipalités, ce qui impliquerait d'autres unités d'analyse. Nous avons choisi de nous concentrer sur les contenus des politiques publiques des États nationaux, susceptibles d'exprimer en euxmêmes une intention et une orientation dans les grandes lignes stratégiques adoptées, indépendamment de leur exécution.

Étant donné les multiples domaines de relation potentielle entre le politique et le religieux, nous avons abordé les sous-dimensions suivantes qui reflètent différents domaines de la gestion publique:

- bioéthique;

- droits sexuels et reproductifs;

- éducation;

- genre;

- développement social et démographique;

- religion;

- sciences et arts;

- communication. 
Évaluer le degré de laïcité en partant d'une analyse de l'autonomie de l'État dans la définition des politiques publiques renvoie à la discussion sur la place occupée par les religions dans un système démocratique. Comment considérer la participation des institutions ou des agents religieux aux débats sur la bioéthique, par exemple, à l'aune de la laïcité de l'État? Devons-nous considérer leur apport au même titre que celui d'autres organisations de la société civile, ou bien les considérer comme une limitation des obligations de l'État, chargé de formuler des programmes gouvernementaux qui concernent différents droits, sans imposer de doctrine particulière? Les particularités historiques et politiques de chaque pays, le rôle qu'y jouent les différentes personnalités ecclésiastiques conditionneront certainement les réponses à ces interrogations. Au moment d'évaluer la participation religieuse aux conseils ou aux comités publics, nous avons décidé de distinguer d'une part entre la présence d'une autorité religieuse proprement dite, et celle d'agents non religieux qui véhiculent des valeurs confessionnelles; et de l'autre, nous nous sommes demandés s'il existait un principe d'équité entre toutes les croyances - religieuses et non religieuses - et leurs représentants, ou si seules étaient présentes les dénominations religieuses prédominantes. Ainsi, l'évaluation ne condamne pas la participation des acteurs religieux en tant que tels, mais il surveille la présence équitable de toutes les voix confessionnelles et non confessionnelles sur la scène publique.

Il s'avère intéressant de nous arrêter sur l'indicateur «autorisation de traitements médicaux alternatifs dans les services publics de santé pour des raisons de croyance». Étant donné que la liberté de conscience est une composante constitutive de la laïcité, la note sera plus élevée si l'État, dans son système public de santé, accepte qu'un témoin de Jehova refuse la transfusion et envisage la possibilité d'autres procédés.

Dans le domaine éducatif, l'enseignement religieux dans les institutions éducatives publiques exige quelques précisions. Tout d'abord on évalue si l'enseignement y est doctrinaire, quelle que soit la doctrine enseignée. Puis on analyse si la législation la prévoit ou l'interdit, ou bien ni l'un ni l'autre. Cette situation hybride se rencontre en Argentine: bien que l'éducation soit perçue dans l'imaginaire collectif comme une éducation laïque, les imprécisions normatives font que des cours de religion sont enseignés dans certaines écoles publiques du pays.

On retrouve cette même gradation - permission, non-régulation et interdiction - dans d'autres indicateurs, comme celui de «reconnaissance du mariage entre personnes du même sexe » de la sous-dimension "genre ». Les nuances enrichissent l'observation et permettent un relevé plus précis de l'état de cette situation particulière. 
Tableau 2 : dimension "Politiques publiques"

\begin{tabular}{|c|c|c|}
\hline Dimension & Sous-dimension & Indicateurs \\
\hline \multirow[t]{5}{*}{$\begin{array}{l}\text { Politiques } \\
\text { publiques } \\
(45 \%)\end{array}$} & a) bioéthique & $\begin{array}{l}\text { I) Participation des ministres de culte/agents religieux } \\
\text { aux Comités nationaux de Bioéthique } \\
(20 \%) \\
- \text { Uniquement les Églises principales } \\
0 \\
\text { - Autres agents non formellement religieux qui véhi- } \\
\text { culent des valeurs religieuses } \\
1 \\
\text { - Représentants de toutes les croyances (religieuses et } \\
\text { philosophiques) } \\
2 \\
- \text { Aucun } \\
4\end{array}$ \\
\hline & & $\begin{array}{l}\text { II) Autorisation de l'euthanasie ou de toute forme de } \\
\text { décès assisté } \\
(17 \%) \\
- \text { Non } \\
0 \\
- \text { Oui, de manière passive } \\
2 \\
- \text { Oui, de manière active } \\
4\end{array}$ \\
\hline & & $\begin{array}{l}\text { III) Autorisation de la recherche sur les cellules mères } \\
(17 \%) \\
- \text { Non } \\
0 \\
- \text { Oui } \\
4\end{array}$ \\
\hline & & $\begin{array}{l}\text { IV) Autorisation de la reproduction assistée } \\
(17 \%) \\
- \text { Non } \\
0 \\
- \text { Uniquement pour les hétérosexuels } \\
1 \\
- \text { Oui } \\
4\end{array}$ \\
\hline & & $\begin{array}{l}\text { V) Autorisation de traitements médicaux alternatifs } \\
\text { dans les services publics de santé pour raison de } \\
\text { croyance (transfusions de sang) } \\
(12 \%) \\
- \text { Non } \\
0 \\
- \text { Oui } \\
4\end{array}$ \\
\hline
\end{tabular}




\begin{tabular}{|c|c|c|}
\hline Dimension & Sous-dimension & Indicateurs \\
\hline & & $\begin{array}{l}\text { VI) Autorisation des opérations de changement de sexe } \\
\text { dans les services publics de santé } \\
(17 \%) \\
- \text { Non } \\
0 \\
- \text { Sans régulation } \\
1 \\
- \text { Oui } \\
4\end{array}$ \\
\hline \multirow[t]{4}{*}{$\begin{array}{l}\text { Politiques } \\
\text { publiques }\end{array}$} & $\begin{array}{l}\text { b) Droits sexuels } \\
\text { et reproductifs }\end{array}$ & $\begin{array}{l}\text { I) Législation sur l'avortement }(20 \%) \\
\text { - Interdit dans tous les cas } \\
0 \\
\text { - En cas de risque pour la vie de la femme } \\
1 \\
\text { - En cas de risque pour la santé de la femme } \\
2 \\
\text { - En cas de violence sexuelle } \\
3 \\
\text { - Limité exclusivement par la durée de la gestation } \\
4\end{array}$ \\
\hline & & $\begin{array}{l}\text { II) Accès aux méthodes contraceptives dans les services } \\
\text { publics de santé (préservatifs, diaphragmes) } \\
(11 \%) \\
- \text { Non } \\
0 \\
\text { - Oui } \\
4\end{array}$ \\
\hline & & $\begin{array}{l}\text { III) Accès à des méthodes contraceptives d'urgence dans } \\
\text { les services publics (la pilule du lendemain) } \\
(14 \%) \\
- \text { Non } \\
0 \\
- \text { Uniquement en cas de violence } \\
2 \\
- \text { Oui } \\
4\end{array}$ \\
\hline & & $\begin{array}{l}\text { IV) Information aux victimes de violence sexuelle dans } \\
\text { les services publics de santé } \\
(11 \%) \\
\text { - Possibilité de négation d'information à la victime } \\
0 \\
- \text { Absence de réglementation à ce sujet } \\
1 \\
- \text { Obligation d'information sur les droits légaux } \\
4\end{array}$ \\
\hline
\end{tabular}


INDICATEURS DE LAÏCITÉ DANS DEUX DÉMOCRATIES CONTEMPORAINES - 205

\begin{tabular}{|c|c|c|}
\hline \multirow[t]{7}{*}{ Dimension } & Sous-dimension & Indicateurs \\
\hline & & $\begin{array}{l}\text { V) Promotion de l'abstinence et de la fidélité pour la } \\
\text { prévention du VIH/Sida dans les politiques publiques } \\
(11 \%) \\
\text { - Oui, comme mesure exclusive } \\
0 \\
\text { - Oui, parmi d'autres mesures } \\
1 \\
\text { - Non } \\
4\end{array}$ \\
\hline & & $\begin{array}{l}\text { VI) Programmes d'attention aux droits sexuels et } \\
\text { reproductifs } \\
(11 \%) \\
- \text { Non } \\
0 \\
\text { - Oui } \\
4\end{array}$ \\
\hline & & $\begin{array}{l}\text { VII) Programmes d'attention aux droits sexuels et } \\
\text { reproductifs pour les communautés GLBTI } \\
(11 \%) \\
- \text { Non } \\
0 \\
\text { - Oui } \\
4\end{array}$ \\
\hline & & $\begin{array}{l}\text { VIII) Programmes de santé sexuelle et reproductive des } \\
\text { jeunes et des adolescents } \\
(11 \%) \\
- \text { Non } \\
0 \\
- \text { Avec accord des parents ou tuteurs } \\
1 \\
- \text { Oui } \\
4\end{array}$ \\
\hline & c) Éducation & $\begin{array}{l}\text { I) Programmes d'éducation sexuelle fondés sur des } \\
\text { principes scientifiques } \\
(20 \%) \\
- \text { Non } \\
0 \\
- \text { À partir de l'âge de } 12 \text { ans } \\
2 \\
\text { - En dessous de l'âge de } 12 \text { ans } \\
4\end{array}$ \\
\hline & & $\begin{array}{l}\text { II) Financement des institutions d'éducation religieuses } \\
(20 \%) \\
- \text { Direct } \\
0 \\
- \text { Indirect } \\
1 \\
- \text { Non } \\
4\end{array}$ \\
\hline
\end{tabular}




\begin{tabular}{|c|c|c|}
\hline \multirow[t]{6}{*}{ Dimension } & Sous-dimension & Indicateurs \\
\hline & & $\begin{array}{l}\text { III) Enseignement religieux (ou d'une philosophie } \\
\text { particulière) dans les institutions publiques } \\
\text { d'enseignement } \\
(20 \%) \\
- \text { Prévu dans la législation } \\
0 \\
- \text { Non prévu ni interdit par la législation } \\
2 \\
\text { - Interdit par la législation } \\
4\end{array}$ \\
\hline & & $\begin{array}{l}\text { IV) Participation de ministres de culte/agents religieux à } \\
\text { l'élaboration de politiques/programmes éducatifs } \\
(10 \%) \\
- \text { Oui } \\
0 \\
\text { - Autres agents non formellement religieux qui } \\
\text { véhiculent des valeurs religieuses } \\
1 \\
\text { - Représentants de toutes les croyances religieuses } \\
\text { et philosophiques } \\
2 \\
- \text { Non } \\
4\end{array}$ \\
\hline & & $\begin{array}{l}\text { V) Contenus religieux doctrinaires ou philosophiques } \\
\text { particuliers dans les livres scolaires ou programmes } \\
\text { d'éducation primaire officiels } \\
(10 \%) \\
\text { - Oui } \\
0 \\
- \text { Non } \\
4\end{array}$ \\
\hline & & $\begin{array}{l}\text { VI) Lieux et symboles religieux dans les écoles publiques } \\
(10 \%) \\
- \text { Oui } \\
0 \\
- \text { Non } \\
4\end{array}$ \\
\hline & & $\begin{array}{l}\text { VII) Positionnement officiel sur les fêtes ou pratiques } \\
\text { religieuses dans les écoles publiques } \\
(10 \%) \\
- \text { Soutien } \\
0 \\
- \text { Acceptation par omission des fêtes religieuses } \\
1 \\
\text { - Acceptation des fêtes traditionnelles à fondement } \\
\text { religieux } \\
2 \\
- \text { Interdiction des fêtes religieuses ou de toute fête à } \\
\text { fondement religieux } \\
4\end{array}$ \\
\hline
\end{tabular}




\begin{tabular}{|c|c|c|}
\hline \multirow[t]{7}{*}{ Dimension } & Sous-dimension & Indicateurs \\
\hline & $\begin{array}{l}\text { d) Genre } \\
(12,5 \%)\end{array}$ & $\begin{array}{l}\text { I) Politiques et/ou programmes de promotion de } \\
\text { l'égalité des genres } \\
(20 \%) \\
- \text { Non } \\
0 \\
- \text { Oui } \\
4\end{array}$ \\
\hline & & $\begin{array}{l}\text { II) Politiques séculaires de lutte contre la violence } \\
\text { intrafamiliale (refuges, assistance juridique, tribunaux } \\
\text { spéciaux) } \\
(10 \%) \\
- \text { Non } \\
0 \\
\text { - Uniquement pour les femmes, sans inclusion des } \\
\text { enfants, garçons et filles } \\
2 \\
\text { - Oui, pour tous } \\
4\end{array}$ \\
\hline & & $\begin{array}{l}\text { III) Politiques qui établissent des quotas pour les } \\
\text { femmes à des postes d'élues } \\
(10 \%) \\
- \text { Non } \\
0 \\
- \text { Oui } \\
4\end{array}$ \\
\hline & & $\begin{array}{l}\text { IV) Politiques de lutte contre l'homophobie et/ou la } \\
\text { lesbianophobie } \\
(10 \%) \\
- \text { Non } \\
0 \\
- \text { Oui } \\
4\end{array}$ \\
\hline & & $\begin{array}{l}\text { V) Reconnaissance des unions civiles ou des PACS entre } \\
\text { personnes du même sexe } \\
(10 \%) \\
- \text { Interdiction } \\
0 \\
\text { - Absence de régulation } \\
1 \\
\text { - Autorisé } \\
4\end{array}$ \\
\hline & & $\begin{array}{l}\text { VI) Reconnaissance du mariage pour tous } \\
(20 \%) \\
- \text { Interdiction } \\
0 \\
- \text { Sans régulation } \\
1 \\
- \text { Autorisation } \\
4\end{array}$ \\
\hline
\end{tabular}




\begin{tabular}{|c|c|c|}
\hline \multirow[t]{6}{*}{ Dimension } & Sous-dimension & Indicateurs \\
\hline & $\begin{array}{l}\text { e) Développement } \\
\text { social et } \\
\text { démographique } \\
(12,5 \%)\end{array}$ & $\begin{array}{l}\text { I) Participation des ministres du culte/agents } \\
\text { religieux dans la définition de politiques sociales de } \\
\text { développement } \\
(15 \%) \\
\text { - Oui } \\
0 \\
- \text { - Autres agents qui véhiculent des valeurs religieuses } \\
1 \\
\text { - Représentants de toutes les croyances religieuses ou } \\
\text { philosophiques } \\
2 \\
- \text { Non } \\
4\end{array}$ \\
\hline & & $\begin{array}{l}\text { II) Participation des ministres du culte/agents religieux } \\
\text { à l'application de programmes gouvernementaux ou de } \\
\text { programmes d'assistance à la pauvreté } \\
(15 \%) \\
\text { - Oui } \\
0 \\
\text { - Autres agents avec fondement religieux qui appliquent } \\
\text { les programmes } \\
1 \\
\text { - Représentants de toutes les croyances religieuses ou } \\
\text { philosophiques } \\
2 \\
- \text { Non } \\
4\end{array}$ \\
\hline & & $\begin{array}{l}\text { III) Participation des ministres du culte à la gestion } \\
\text { de programmes gouvernementaux d'appui à la } \\
\text { participation sociale (Coopératives, migrants, auto } \\
\text { emploi) } \\
(15 \%) \\
\text { - Oui } \\
0 \\
\text { - Non } \\
4\end{array}$ \\
\hline & & $\begin{array}{l}\text { IV) Participation de ministres rdu culte à la gestion de } \\
\text { programmes gouvernementaux d'options productives } \\
\text { - PME } \\
(15 \%) \\
- \text { Oui } \\
0 \\
- \text { Non } \\
4\end{array}$ \\
\hline & & $\begin{array}{l}\text { V) Assignation de fonds publics aux institutions } \\
\text { religieuses/ONG d'obédience religieuse dans la gestion } \\
\text { de programmes sociaux } \\
(20 \%) \\
\text { - Oui } \\
0 \\
- \text { Non } \\
4\end{array}$ \\
\hline
\end{tabular}




\begin{tabular}{|c|c|c|}
\hline Dimension & Sous-dimension & Indicateurs \\
\hline & & $\begin{array}{l}\text { VI) Politiques de population à contenu religieux/ONG } \\
\text { d'obédience religieuse dans la gestion de programmes } \\
\text { sociaux (maternité, famille, soins des enfants, } \\
\text { abstinence? fidélité ?) } \\
(20 \%) \\
\text { - Oui } \\
0 \\
\text { - Non } \\
4\end{array}$ \\
\hline \multirow[t]{5}{*}{$\begin{array}{l}\text { Politiques } \\
\text { publiques }\end{array}$} & f) Religion & $\begin{array}{l}\text { I) Utilisation de fonds publics et promotion de fêtes ou } \\
\text { pratiques religieuses institutionnalisées } \\
(22 \%) \\
- \text { Oui } \\
0 \\
- \text { Non } \\
4\end{array}$ \\
\hline & & $\begin{array}{l}\text { II) Participation officielle de hauts fonctionnaires aux } \\
\text { cérémonies religieuses de culte public - Te Deum, ou } \\
\text { autres } \\
(22 \%) \\
- \text { Oui } \\
0 \\
\text { - Non } \\
4\end{array}$ \\
\hline & & $\begin{array}{l}\text { III) Lieux et symboles religieux dans les institutions } \\
\text { publiques - pouvoirs exécutif, législatif, judiciaire (sauf } \\
\text { les institutions éducatives) } \\
(17 \%) \\
- \text { Oui } \\
0 \\
- \text { Non } \\
4\end{array}$ \\
\hline & & $\begin{array}{l}\text { IV) Présence d'une invocation religieuse dans la } \\
\text { prestation de serment à des postes publics ou lors de } \\
\text { témoignages juridiques } \\
(17 \%) \\
- \text { Oui, obligatoirement } \\
0 \\
- \text { Oui, mais parmi d'autres options non religieuses } \\
2 \\
- \text { Non } \\
4\end{array}$ \\
\hline & & $\begin{array}{l}\text { V) Présence de toute argumentation religieuse dans les } \\
\text { décisions de la Cour Suprême } \\
(22 \%) \\
- \text { Oui } \\
0 \\
- \text { Non } \\
4\end{array}$ \\
\hline
\end{tabular}




\begin{tabular}{|c|c|c|}
\hline \multirow[t]{6}{*}{ Dimension } & Sous-dimension & Indicateurs \\
\hline & $\begin{array}{l}\text { g) Sciences et Arts } \\
(12,5 \%)\end{array}$ & $\begin{array}{l}\text { I) Liberté de chaire, de recherche et de divulgation } \\
(50 \%) \\
- \text { Non } \\
0 \\
- \text { Oui } \\
4\end{array}$ \\
\hline & & $\begin{array}{l}\text { II) Censure des œuvres d'art et de la production } \\
\text { culturelle } \\
(50 \%) \\
- \text { Oui } \\
0 \\
- \text { Non } \\
4\end{array}$ \\
\hline & $\begin{array}{l}\text { h) Communication } \\
(12,5 \%)\end{array}$ & $\begin{array}{l}\text { I) Censure dans les médias pour des raisons religieuses } \\
(30 \%) \\
- \text { Oui } \\
0 \\
- \text { Non } \\
4\end{array}$ \\
\hline & & $\begin{array}{l}\text { II) Programmes de doctrine religieuse dans les } \\
\text { institutions étatiques } \\
(40 \%) \\
- \text { Oui } \\
0 \\
- \text { Non } \\
4\end{array}$ \\
\hline & & $\begin{array}{l}\text { III) Interdiction de manifestation d'expression religieuse } \\
\text { dans les médias } \\
(30 \%) \\
- \text { Oui } \\
0 \\
\text { - En situation extraordinaire } \\
2 \\
- \text { Non } \\
4\end{array}$ \\
\hline
\end{tabular}

\section{Culture politique}

Appréhendée à l'aune des imaginaires et des représentations collectives qui constituent le répertoire des pratiques naturalisées et qui façonnent le modus operandi des décideurs politiques, la culture politique ne répond pas exclusivement à la législation en vigueur ni à la mise en place d'un programme précis de gouvernement, mais plutôt à une culture politique instituée. La promotion de l'identité nationale à partir de symboles religieux, la participation d'agents religieux aux inaugurations de travaux publics, la participation des autorités confessionnelles durant les processus électoraux, la présence de symboles religieux dans les édifices publics, la réalisation du Te Deum, sont autant 
d'éléments fondamentaux qui permettent d'évaluer la culture politique au sein des coordonnées analytiques que nous avons explicitées. Il s'agit d'identifier des pratiques naturalisées, qui se reproduisent inconsciemment, parce qu'ancrées dans l'idiosyncrasie politique dominante.

La culture politique est particulièrement sensible aux indicateurs suivants:

I) Promotion de l'identité nationale à travers les symboles religieux;

II) Participation d'agents religieux à l'inauguration de travaux publics;

III) Participation des institutions ou des agents religieux aux processus d'élection des hauts fonctionnaires;

IV) Jurisprudence tendant à respecter les cultures particulières du pays (multiculturalisme, accommodements raisonnables);

V) Politiques publiques tendant à la sacralisation de symboles civiques (drapeaux, héros nationaux);

VI) Réunion entre mandataires gouvernementaux et leaders religieux pour l'élaboration et/ou l'application de politiques publiques;

VII) Rencontres entre élus et leaders religieux;

VIII) Invocation de symboles et de références religieuses dans les discours politiques dans un but de prosélytisme;

IX) Exposition de la part de l'État de symboles/espaces religieux dans les lieux publics non gouvernementaux (hôpitaux, aéroports, places publiques);

$\mathrm{X)}$ Assistance religieuse dans les lieux de réclusion I: les forces armées;

$\mathrm{XI})$ Assistance religieuse dans les lieux de réclusion II: les unités pénitentiaires

XII) Assistance religieuse dans les lieux d'isolement: les hôpitaux

XIII) Utilisation des fonds publics pour les «traditions» ou les manifestations religieuses populaires non institutionnelles

XIV) Promotion étatique d'une culture de la pluralité et de la diversité dans les médias.

En fonction des critères sous-jacents à la définition de la laïcité, nous nous sommes limités à la gestion de l'État pour évaluer la présence de symboles ou d'espaces religieux dans le domaine public, sans analyser les initiatives qui pourraient venir de la société civile. On distinguera ici entre l'affichage de symboles d'un seul culte dans les espaces publics et l'existence d'un espace interreligieux (par exemple dans les aéroports). Il ne faut pas confondre un état pluriconfessionnel et un état laïc, même si la reconnaissance par l'État d'une pluralité religieuse obtient une note élevée. Cependant, un État qui ne contemple l'implantation d'aucun symbole religieux dans les espaces publics obtient un niveau maximum de laïcité.

Les catégories correspondantes à l'indicateur «assistance religieuse dans les espaces de réclusion ou d'isolement (forces armées, hôpitaux, unités pénitentiaires) » requièrent un travail minutieux de composition. En effet, au moment de mettre en rapport le principe d'autonomie de l'État et celui de la liberté de conscience des individus, nous nous sommes retrouvés face à un éventail de possibilités qui devaient être contemplées par l'outil de mesure. L'interdiction de toute pratique religieuse est aussi pénalisée que l'autorisation 
légale d'exercer un monopole religieux de l'assistance confessionnelle dans les lieux de réclusion. Dans une séquence intermédiaire, il est précisé s'il n'existe de fait qu'un seul culte dans les contextes institutionnels mentionnés, ou si au contraire toutes les religions peuvent exercer leur activité confessionnelle. Les États qui garantissent légalement à toutes les religions le droit d'exercer une pratique confessionnelle dans les lieux de réclusion obtiennent une note élevée, mais les États qui autorisent cette assistance lorsqu'elle vient d'une demande personnelle et volontaire de l'individu obtiennent la note maximum.

\section{Tableau 3 : dimension "Culture politique"}

\begin{tabular}{|c|c|}
\hline Dimension & Indicateurs \\
\hline \multirow[t]{5}{*}{$\begin{array}{l}\text { Culture } \\
\text { Politique }\end{array}$} & $\begin{array}{l}\text { I) Promotion de l'identité nationale à travers des symboles religieux } \\
(5 \%) \\
- \text { Oui } \\
0 \\
- \text { Non } \\
4\end{array}$ \\
\hline & $\begin{array}{l}\text { II) Participation d'agents religieux à l'inauguration de travaux publics } \\
(10 \%) \\
- \text { Oui } \\
0 \\
- \text { Parfois } \\
2 \\
- \text { Non } \\
4\end{array}$ \\
\hline & $\begin{array}{l}\text { III) Participation d'institutions ou d'agents religieux au processus électoral } \\
(15 \%) \\
\text { - Directement } \\
0 \\
- \text { Indirectement } \\
1 \\
- \text { Non } \\
4\end{array}$ \\
\hline & $\begin{array}{l}\text { IV) Jurisprudence tendant à respecter les cultures particulières dans } \\
\text { le pays, multiculturalisme, accommodements raisonnables } \\
(5 \%) \\
- \text { Non } \\
0 \\
- \text { Oui } \\
4\end{array}$ \\
\hline & $\begin{array}{l}\text { V) Politiques publiques tendant à la sacralisation de symboles civiques } \\
(5 \%) \\
- \text { Oui } \\
0 \\
- \text { Non } \\
4\end{array}$ \\
\hline
\end{tabular}




\begin{tabular}{|c|c|}
\hline \multirow{6}{*}{ Dimension } & Indicateurs \\
\hline & $\begin{array}{l}\text { VI) Réunions entre hauts fonctionnaires et responsables religieux pour } \\
\text { l'élaboration ou l'application de politiques publiques } \\
(15 \%) \\
- \text { Oui } \\
0 \\
- \text { Non } \\
4\end{array}$ \\
\hline & $\begin{array}{l}\text { VII) Rencontres entre élus et responsables religieux } \\
(5 \%) \\
- \text { Oui } \\
0 \\
- \text { Non } \\
4\end{array}$ \\
\hline & 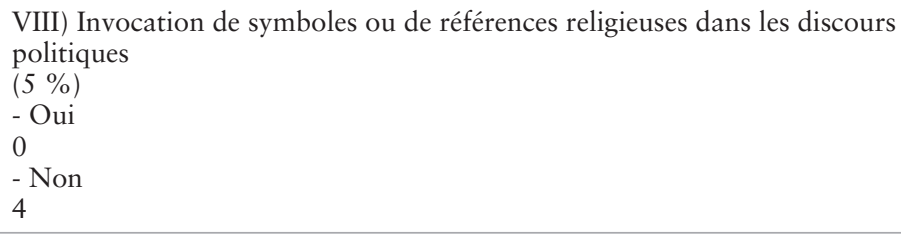 \\
\hline & $\begin{array}{l}\text { IX) Affichage par l'État de symboles/espaces religieux dans les lieux } \\
\text { publics non gouvernementaux (hôpitaux, aéroports, places publiques) } \\
(10 \%) \\
\text { - Oui, mais d'un seul culte } \\
0 \\
\text { - Espace interreligieux } \\
2 \\
- \text { Non } \\
4\end{array}$ \\
\hline & $\begin{array}{l}\text { X) Assistance religieuse dans les lieux de réclusion } \\
1: \text { forces armées } \\
(5 \%) \\
- \text { Non ou Oui, dans les espaces définis par une seule religion } \\
0 \\
\text { - Autorisation de fait, mais pour une seule religion } \\
1 \\
\text { - De fait pour toutes les religions } \\
2 \\
- \text { Garantie juridique pour toutes les religions } \\
3 \\
- \text { Personnellement demandée } \\
4\end{array}$ \\
\hline
\end{tabular}




\begin{tabular}{|c|c|}
\hline \multirow[t]{5}{*}{ Dimension } & Indicateurs \\
\hline & $\begin{array}{l}\text { XI) Assistance religieuse dans les lieux de réclusion } \\
\text { II: unités pénitentiaires } \\
(5 \%) \\
- \text { Non ou Oui, dans les espaces définis par une seule religion } \\
0 \\
\text { - Autorisation de fait, mais pour une seule religion } \\
1 \\
\text { - De fait pour toutes les religions } \\
2 \\
\text { - Garantie juridique pour toutes les religions } \\
3 \\
- \text { Personnellement demandée } \\
4\end{array}$ \\
\hline & $\begin{array}{l}\text { XII) Assistance religieuse dans des lieux d'isolement: hôpitaux } \\
(5 \%) \\
- \text { Non ou Oui, dans les espaces définis par une seule religion } \\
\text { - Autorisation de fait, mais pour une seule religion } \\
1 \\
- \text { De fait pour toutes les religions } \\
2 \\
- \text { Garantie juridique pour toutes les religions } \\
3 \\
- \text { Personnellement demandée } \\
4\end{array}$ \\
\hline & $\begin{array}{l}\text { XIII) Utilisation des fonds publics pour les «traditions» ou } \\
\text { manifestations religieuses populaires non institutionnelles } \\
(5 \%) \\
- \text { Oui } \\
0 \\
- \text { Non } \\
4\end{array}$ \\
\hline & $\begin{array}{l}\text { XIV) Promotion par l'État d'une culture de la pluralité et de la diversité } \\
\text { dans les médias } \\
(5 \%) \\
- \text { Non } \\
0 \\
- \text { Oui } \\
4\end{array}$ \\
\hline
\end{tabular}




\section{Le Mexique et l'Argentine}

Tableau 4 : Normativité juridique au Mexique et en Argentine

\begin{tabular}{|c|c|c|c|c|}
\hline \multicolumn{5}{|l|}{ Laïcité } \\
\hline Dimension & Sous-dimension & Indicateurs & Mexique & Argentine \\
\hline \multirow[t]{5}{*}{$\begin{array}{l}\text { Normativité } \\
\text { juridique }\end{array}$} & $\begin{array}{l}\text { a) Fondement } \\
\text { et caractère de } \\
\text { l'État }\end{array}$ & $\begin{array}{l}\text { I) Type d'invocation qui est à } \\
\text { l'origine de la légitimité de l'État } \\
\text { - Dieu/autre figure religieuse } \\
0 \\
\text { - Dieu/Souveraineté populaire } \\
1 \\
\text { - Aucune } \\
2 \\
\text { - Souveraineté populaire } \\
4\end{array}$ & $4(4,5)$ & $0(0)$ \\
\hline & & $\begin{array}{l}\text { II) Définition de l'État en matière } \\
\text { religieuse } \\
\text { - Religion officielle/État athée } \\
0 \\
\text { - Religion privilégiée ou nationale } \\
1 \\
\text { - Référence au principe de } \\
\text { séparation } \\
3 \\
\text { - Laïque } \\
4\end{array}$ & $3(6,75 \%)$ & $1(2,25)$ \\
\hline & & $\begin{array}{l}\text { III) Référence à des éléments } \\
\text { religieux parmi les symboles de } \\
\text { la patrie } \\
\text { - Oui } \\
0 \\
- \text { Non } \\
4\end{array}$ & $4(4,5)$ & $4(4,5)$ \\
\hline & $\begin{array}{l}\text { b) Relation } \\
\text { État/Institutions } \\
\text { religieuses }\end{array}$ & $\begin{array}{l}\text { I) Concordat/Accords avec les } \\
\text { institutions religieuses } \\
- \text { Oui } \\
0 \\
- \text { Non } \\
4\end{array}$ & $4(7,6)$ & $0(0)$ \\
\hline & & $\begin{array}{l}\text { II) Financement étatique à des } \\
\text { fins religieuses } \\
\text { - Contribution directe de l'État } \\
0 \\
\text { - Exemptions fiscales pour les } \\
\text { institutions religieuses } \\
1 \\
\text { - Apports fiscaux par décision } \\
\text { individuelle } \\
2 \\
- \text { Sans financement } \\
4\end{array}$ & $1(1,9)$ & $0(0)$ \\
\hline
\end{tabular}




\begin{tabular}{|c|c|c|c|c|}
\hline \multicolumn{5}{|l|}{ Laïcité } \\
\hline \multirow[t]{6}{*}{ Dimension } & Sous-dimension & Indicateurs & Mexique & Argentine \\
\hline & & $\begin{array}{l}\text { III) Type de procuration/ } \\
\text { personnalité juridique des } \\
\text { institutions religieuses } \\
\text { - Publique } \\
0 \\
\text { - Sans procuration } \\
1 \\
\text { - Privée } \\
4\end{array}$ & $4(3,8)$ & $0(0)$ \\
\hline & & $\begin{array}{l}\text { IV) Types d'enregistrement } \\
\text { du culte } \\
- \text { Obligatoire différencié } \\
0 \\
- \text { Optatif différencié } \\
1 \\
- \text { Obligatoire égalitaire } \\
2 \\
- \text { Optatif égalitaire } \\
3 \\
- \text { Sans enregistrement } \\
4\end{array}$ & $3(2,85)$ & $0(0)$ \\
\hline & & $\begin{array}{l}\text { V) Tribunaux religieux exclusifs } \\
\text { interdisant l'exercice de la } \\
\text { législation nationale } \\
\text { - Oui } \\
0 \\
\text { - Non } \\
4\end{array}$ & $4(1,9)$ & $4(1,9)$ \\
\hline & & $\begin{array}{l}\text { VI) Rituels religieux durant les } \\
\text { cérémonies officielles } \\
- \text { Prévu légalement } \\
0 \\
- \text { Non prévu légalement } \\
2 \\
- \text { Légalement interdit } \\
4\end{array}$ & $4(3,8)$ & $2(1,9)$ \\
\hline & & $\begin{array}{l}\text { VII) Registres civils des } \\
\text { naissances, mariages et décès } \\
- \text { Non } \\
0 \\
\text { - Reconnaissance civile des } \\
\text { registres religieux } \\
1 \\
\text { - Oui } \\
4\end{array}$ & $4(3,8)$ & $4(3,8)$ \\
\hline
\end{tabular}




\begin{tabular}{|c|c|c|c|c|}
\hline \multicolumn{5}{|l|}{ Laïcité } \\
\hline \multirow[t]{8}{*}{ Dimension } & Sous-dimension & Indicateurs & Mexique & Argentine \\
\hline & & $\begin{array}{l}\text { VIII) Ingérence de l'État dans } \\
\text { les affaires intérieures des } \\
\text { institutions religieuses } \\
\text { - Oui } \\
0 \\
\text { - Non } \\
4\end{array}$ & $4(3,8)$ & $4(3,8)$ \\
\hline & & $\begin{array}{l}\text { IX) Restrictions légales au droit à } \\
\text { la conversion ou au prosélytisme } \\
\text { religieux } \\
\text { - Oui } \\
0 \\
\text { - Non } \\
4\end{array}$ & $4(1,9)$ & $4(1,9)$ \\
\hline & $\begin{array}{l}\text { c) Garantie } \\
\text { des droits } \\
\text { fondamentaux }\end{array}$ & $\begin{array}{l}\text { I) Reconnaissance de la liberté de } \\
\text { conscience et/ou de croyance et } \\
\text { de culte } \\
- \text { Non } \\
0 \\
\text { - Oui } \\
4\end{array}$ & $4(4,75)$ & $4(4,75)$ \\
\hline & & $\begin{array}{l}\text { II) Limitation de l'accès aux } \\
\text { postes publics pour raisons de } \\
\text { croyance } \\
\text { - Oui } \\
0 \\
\text { - Non } \\
4\end{array}$ & $4(4,75)$ & $4(4,75)$ \\
\hline & & $\begin{array}{l}\text { III) Reconnaissance de la } \\
\text { diversité comme valeur } \\
- \text { Non } \\
0 \\
\text { - Oui, en termes } \\
\text { antidiscriminatoires } \\
2 \\
- \text { Oui, en termes de réaffirmation } \\
4\end{array}$ & $2(2,38)$ & $2(2,38)$ \\
\hline & & $\begin{array}{l}\text { IV) Ratification du Protocole } \\
\text { facultatif de la CEDAW } \\
\text { - Non } \\
0 \\
- \text { Oui } \\
4\end{array}$ & $4(4,75)$ & $4(4,75)$ \\
\hline & & $\begin{array}{l}\text { V) Respect de l'autonomie } \\
\text { reproductive } \\
- \text { Non } \\
0 \\
- \text { Oui } \\
4\end{array}$ & $4(4,75)$ & $4(4,75)$ \\
\hline
\end{tabular}




\begin{tabular}{|c|c|c|c|c|}
\hline \multicolumn{5}{|l|}{ Laïcité } \\
\hline \multirow[t]{5}{*}{ Dimension } & Sous-dimension & Indicateurs & Mexique & Argentine \\
\hline & $\begin{array}{l}\text { Garantie } \\
\text { des droits } \\
\text { fondamentaux }\end{array}$ & $\begin{array}{l}\text { VI) Éducation laïque } \\
- \text { Non } \\
0 \\
\text { - Oui } \\
4\end{array}$ & $4(4,75)$ & $4(4,75)$ \\
\hline & & $\begin{array}{l}\text { VII) Objection de conscience } \\
\text { dans les services publics } \\
\text { - En aucun cas } \\
0 \\
\text { - Oui, dans tous les cas } \\
1 \\
\text { - Uniquement quand il s'agit de } \\
\text { respecter les droits d'un tiers } \\
4\end{array}$ & $0(0)$ & $4(4,75)$ \\
\hline & & $\begin{array}{l}\text { VIII) Pénalisation de } \\
\text { l'homosexualité } \\
\text { - Oui } \\
0 \\
- \text { Non } \\
4\end{array}$ & $4(4,75)$ & $4(4,75)$ \\
\hline & $\begin{array}{l}\text { Total } \\
\text { Normativité } \\
\text { juridique }\end{array}$ & $69(77,98)$ & $53(55,68)$ & \\
\hline
\end{tabular}

Élaboration des auteurs, 2014

\section{Tableau 5 : Politiques publiques au Mexique et en Argentine}

\begin{tabular}{|c|c|c|c|c|}
\hline \multicolumn{5}{|l|}{ Laïcité } \\
\hline Dimension & Sous-dimension & Indicateurs & Mexique & Argentine \\
\hline $\begin{array}{l}\text { Politiques } \\
\text { Publiques }\end{array}$ & a) Bioéthique & $\begin{array}{l}\text { I) Participation des ministres du } \\
\text { culte/agents religieux aux comités } \\
\text { de bioéthique nationaux } \\
\text { - Uniquement des Églises } \\
\text { prédominantes } \\
0 \\
\text { - Autres agents formellement non } \\
\text { religieux qui véhiculent des valeurs } \\
\text { religieuses } \\
1 \\
\text { - Représentants de toutes } \\
\text { les croyances (religieuses et } \\
\text { philosophiques) } \\
2 \\
- \text { Non-participation } \\
4\end{array}$ & $1(0,88)$ & $0(0)$ \\
\hline
\end{tabular}




\begin{tabular}{|c|c|c|c|c|}
\hline \multicolumn{5}{|l|}{ Laïcité } \\
\hline \multirow[t]{7}{*}{ Dimension } & Sous-dimension & Indicateurs & Mexique & Argentine \\
\hline & & $\begin{array}{l}\text { II) Autorisation de l'euthanasie ou } \\
\text { d'une autre forme de décès assisté } \\
\text { - Non } \\
0 \\
\text { - Oui } \\
4\end{array}$ & $2(1,49)$ & $2(1,49)$ \\
\hline & & $\begin{array}{l}\text { III) Autorisation de la recherche sur } \\
\text { les cellules mères } \\
- \text { Non } \\
0 \\
- \text { Oui } \\
4\end{array}$ & $4(2,98)$ & $4(2,98)$ \\
\hline & & $\begin{array}{l}\text { IV) Autorisation de la reproduction } \\
\text { assistée } \\
- \text { Non } \\
0 \\
- \text { Oui } \\
4\end{array}$ & $4(2,98)$ & $4(2,98)$ \\
\hline & & $\begin{array}{l}\text { V) Autorisation de traitements } \\
\text { alternatifs dans les services publics } \\
\text { de santé pour raisons de croyance } \\
\text { (transfusions de sang) } \\
\text { - Non } \\
0 \\
\text { - Oui } \\
4\end{array}$ & $4(2,1)$ & $4(2,1)$ \\
\hline & & $\begin{array}{l}\text { VI) Autorisation d'opération } \\
\text { de changement de sexe dans les } \\
\text { services publics de santé } \\
\text { - Non } \\
0 \\
\text { - Sans régulation } \\
1 \\
\text { - Oui } \\
4\end{array}$ & $0(0)$ & $4(2,98)$ \\
\hline & $\begin{array}{l}\text { b) Droits } \\
\text { sexuels et } \\
\text { reproductifs }\end{array}$ & $\begin{array}{l}\text { I) Législation sur l'avortement } \\
\text { - Interdit dans tous les cas } \\
0 \\
\text { - Risque pour la vie de la femme } \\
1 \\
\text { - Risque pour la santé de la femme } \\
2 \\
\text { - Violence sexuelle } \\
3 \\
\text { - Prise en compte exclusive de la } \\
\text { gestation } \\
4\end{array}$ & $3(2,63)$ & $3(2,63)$ \\
\hline
\end{tabular}




\begin{tabular}{|c|c|c|c|c|}
\hline \multicolumn{5}{|l|}{ Laïcité } \\
\hline Dimension & Sous-dimension & Indicateurs & Mexique & Argentine \\
\hline & & $\begin{array}{l}\text { II) Accès aux méthodes contracep- } \\
\text { tives dans les services publics de } \\
\text { santé (préservatifs, diaphragmes) } \\
\text { - Non } \\
0 \\
\text { - Oui } \\
4\end{array}$ & $4(1,93)$ & $4(1,93)$ \\
\hline & & $\begin{array}{l}\text { III) Accès aux méthodes contracep- } \\
\text { tives d'urgence dans les services } \\
\text { publics de santé (la pilule du } \\
\text { lendemain) } \\
\text { - Non } \\
0 \\
\text { - Uniquement en cas de violence } \\
\text { sexuelle } \\
2 \\
- \text { Oui } \\
4\end{array}$ & $4(2,45)$ & $4(2,45)$ \\
\hline & & $\begin{array}{l}\text { IV) Information aux victimes de } \\
\text { violence sexuelle dans les services } \\
\text { publics de santé } \\
\text { - Possibilité de nier toute informa- } \\
\text { tion à la victime } \\
0 \\
\text { - Absence de réglementation } \\
1 \\
\text { - Obligation d'information sur les } \\
\text { droits légaux } \\
4\end{array}$ & $4(1,93)$ & $4(1,93)$ \\
\hline & & $\begin{array}{l}\text { V) Promotion de l'abstinence et } \\
\text { de la fidélité dans les politiques } \\
\text { publiques pour la prévention du } \\
\text { VIH/Sida } \\
\text { - Oui, comme mesure exclusive } \\
0 \\
\text { - Oui, comme mesure parmi } \\
\text { d'autres } \\
1 \\
- \text { Non } \\
4\end{array}$ & $1(0,48)$ & $4(1,93)$ \\
\hline & & $\begin{array}{l}\text { VI) Attention aux droits sexuels et } \\
\text { reproductifs } \\
- \text { Non } \\
0 \\
- \text { Oui } \\
4\end{array}$ & $4(1,93)$ & $4(1,93)$ \\
\hline
\end{tabular}




\begin{tabular}{|c|c|c|c|c|}
\hline \multicolumn{5}{|l|}{ Laïcité } \\
\hline Dimension & Sous-dimension & Indicateurs & Mexique & Argentine \\
\hline & & $\begin{array}{l}\text { VII) Attention aux droits sexuels et } \\
\text { reproductifs pour les communautés } \\
\text { LGBTI } \\
\text { - Non } \\
0 \\
- \text { Oui } \\
4\end{array}$ & $4(1,93)$ & $4(1,93)$ \\
\hline & & $\begin{array}{l}\text { VIII) Programmes d'attention à la } \\
\text { santé sexuelle et reproductive pour } \\
\text { les jeunes et les adolescents } \\
\text { - Non } \\
0 \\
\text { - Avec consentement des parents ou } \\
\text { tuteurs } \\
1 \\
\text { - Oui } \\
4\end{array}$ & $4(1,93)$ & $4(1,93)$ \\
\hline & c) Éducation & $\begin{array}{l}\text { I) Programmes d'éducation } \\
\text { sexuelle fondés sur des principes } \\
\text { scientifiques } \\
- \text { Non } \\
0 \\
\text { - À partir de l'âge de } 12 \text { ans } \\
2 \\
- \text { Pour les moins de } 12 \text { ans } \\
4\end{array}$ & $4(3,5)$ & $4(3,5)$ \\
\hline & & $\begin{array}{l}\text { II) Financement des institutions } \\
\text { éducatives religieuses } \\
\text { - Direct } \\
0 \\
- \text { Indirect } \\
1 \\
- \text { Non } \\
4\end{array}$ & $4(3,5)$ & $4(3,5)$ \\
\hline & & $\begin{array}{l}\text { III) Enseignement religieux (ou } \\
\text { d'une philosophie particulière) } \\
\text { dans les institutions d'éducation } \\
\text { publique } \\
\text { - Prévu dans la législation } 0 \\
\text { - Non prévu ni interdit par la } \\
\text { législation } 2 \\
\text { - Interdit par la loi } 4\end{array}$ & $4(3,5)$ & $2(1,75)$ \\
\hline
\end{tabular}




\begin{tabular}{|c|c|c|c|c|}
\hline \multicolumn{5}{|l|}{ Laïcité } \\
\hline Dimension & Sous-dimension & Indicateurs & Mexique & Argentine \\
\hline & & $\begin{array}{l}\text { IV) Participation des ministres du } \\
\text { culte/des agents religieux à l'élabo- } \\
\text { ration de politiques/programmes } \\
\text { éducatifs } \\
\text { - Oui } \\
0 \\
\text { - Autres agents non formellement } \\
\text { religieux qui véhiculent des valeurs } \\
\text { religieuses } \\
1 \\
\text { - Représentants de toutes } \\
\text { les croyances religieuses et } \\
\text { philosophiques } \\
2 \\
- \text { Non } \\
4\end{array}$ & $4(1,75)$ & $1(0,44)$ \\
\hline & & $\begin{array}{l}\text { V) Contenus religieux doctrinaires } \\
\text { ou philosophiques particuliers } \\
\text { dans les livres scolaires ou les } \\
\text { programmes éducatifs officiels de } \\
\text { primaire } \\
\text { - Oui } \\
0 \\
\text { - Non } \\
4\end{array}$ & $4(1,75)$ & $4(1,75)$ \\
\hline & & $\begin{array}{l}\text { VI) Lieux et symboles religieux } \\
\text { dans les écoles publiques } \\
\text { - Oui } \\
0 \\
- \text { Non } \\
4\end{array}$ & $4(1,75)$ & $0(0)$ \\
\hline & & $\begin{array}{l}\text { VII) Positionnement officiel sur les } \\
\text { fêtes ou pratiques religieuses dans } \\
\text { les écoles publiques } \\
\text { - Pour } \\
0 \\
\text { - Acceptation par omission des } \\
\text { fêtes religieuses } \\
1 \\
\text { - Acceptation des fêtes } \\
\text { traditionnelles à fondement } \\
\text { religieux } \\
2 \\
\text { - Interdiction des fêtes religieuses } \\
\text { ou à fondement religieux } \\
4\end{array}$ & $2(0,88)$ & $2(0,88)$ \\
\hline & d) Genre & $\begin{array}{l}\text { I) Politiques et/ou programmes de } \\
\text { promotion de l'égalité des genres } \\
- \text { Non } \\
0 \\
- \text { Oui } \\
4\end{array}$ & $4(1,75)$ & $4(1,75)$ \\
\hline
\end{tabular}




\begin{tabular}{|c|c|c|c|c|}
\hline \multicolumn{5}{|l|}{ Laïcité } \\
\hline Dimension & Sous-dimension & Indicateurs & Mexique & Argentine \\
\hline & & $\begin{array}{l}\text { II) Politiques séculières de lutte } \\
\text { contre la violence intrafamiliale } \\
\text { (refuges, assistance juridique, } \\
\text { tribunaux spéciaux) } \\
\text { - Non } \\
0 \\
\text { - Uniquement pour les femmes } \\
\text { (exclusion des enfants) } \\
2 \\
\text { - Oui pour toutes ces catégories } \\
4\end{array}$ & $4(1,75)$ & $4(1,75)$ \\
\hline & & $\begin{array}{l}\text { III) Politiques fixant des quotas } \\
\text { pour l'accès à des femmes à des } \\
\text { postes d'élues } \\
- \text { Non } \\
0 \\
\text { - Oui } \\
4\end{array}$ & $4(1,75)$ & $4(1,75)$ \\
\hline & & $\begin{array}{l}\text { IV) Politiques de lutte contre l'ho- } \\
\text { mophobie et/ou la lesbianophobie } \\
\text { - Non } \\
0 \\
\text { - Oui } \\
4\end{array}$ & $4(1,75)$ & $4(1,75)$ \\
\hline & & $\begin{array}{l}\text { V) Reconnaissance des unions } \\
\text { civiles ou de Pacs entre personnes } \\
\text { du même sexe } \\
\text { - Interdiction } \\
0 \\
- \text { Non régulation } \\
1 \\
\text { - Autorisation } \\
4\end{array}$ & $1(0,44)$ & $4(3,5)$ \\
\hline & & $\begin{array}{l}\text { VI) Reconnaissance du mariage } \\
\text { entre personnes du même sexe } \\
\text { - Interdiction } \\
0 \\
\text { - Sans régulation } \\
1 \\
\text { - Autorisé } \\
4\end{array}$ & $1(0,88)$ & $4(3,5)$ \\
\hline & & $\begin{array}{l}\text { VII) Possibilité d'adoption pour les } \\
\text { couples de même sexe } \\
\text { - Interdit } \\
0 \\
\text { - Sans régulation } \\
1 \\
\text { - Autorisé } \\
4\end{array}$ & $1(0,88)$ & $4(3,5)$ \\
\hline
\end{tabular}




\begin{tabular}{|c|c|c|c|c|}
\hline \multicolumn{5}{|l|}{ Laïcité } \\
\hline Dimension & Sous-dimension & Indicateurs & Mexique & Argentine \\
\hline & $\begin{array}{l}\text { e) } \\
\text { Développement } \\
\text { social et } \\
\text { démographique }\end{array}$ & $\begin{array}{l}\text { I) Participation des ministres du } \\
\text { culte/agents religieux à la définition } \\
\text { de politiques sociales et de } \\
\text { développement } \\
\text { - Oui } \\
0 \\
\text { - Autres agents qui véhiculent des } \\
\text { valeurs religieuses } \\
1 \\
\text { - Représentants de toutes les } \\
\text { croyances qui véhiculent des } \\
\text { valeurs religieuses } \\
2 \\
\text { - Non } \\
4\end{array}$ & $4(2,63)$ & $0(0)$ \\
\hline & & $\begin{array}{l}\text { II) Participation des ministres } \\
\text { du culte/agents religieux à } \\
\text { l'application de programmes } \\
\text { gouvernementaux et d'assistance à } \\
\text { la pauvreté } \\
\text { - Oui } \\
0 \\
\text { - Autres agents d'obédience } \\
\text { religieuse qui appliquent les } \\
\text { programmes } \\
1 \\
\text { - Représentants de toutes } \\
\text { les croyances religieuses ou } \\
\text { philosophiques } \\
2 \\
\text { - Non } \\
4\end{array}$ & $4(2,63)$ & $0(0)$ \\
\hline & & $\begin{array}{l}\text { III) Participation des ministres du } \\
\text { culte à la gestion de programmes } \\
\text { gouvernementaux de stimulation } \\
\text { à la participation sociale } \\
\text { (coopératives, migrants, auto } \\
\text { emploi) } \\
\text { - Oui } \\
0 \\
\text { - Non } \\
4\end{array}$ & $4(2,63)$ & $4(2,63)$ \\
\hline & & $\begin{array}{l}\text { IV) Participation de ministres reli- } \\
\text { gieux à la gestion de programmes } \\
\text { gouvernementaux d'options } \\
\text { productives (PME) } \\
\text { - Oui } \\
0 \\
- \text { Non } \\
4\end{array}$ & $4(2,63)$ & $4(2,63)$ \\
\hline
\end{tabular}




\begin{tabular}{|c|c|c|c|c|}
\hline \multicolumn{5}{|l|}{ Laïcité } \\
\hline \multirow[t]{7}{*}{ Dimension } & Sous-dimension & Indicateurs & Mexique & Argentine \\
\hline & & $\begin{array}{l}\text { V) Assignation de fonds } \\
\text { économiques publics aux } \\
\text { institutions religieuses/ONG à } \\
\text { fondement religieux dans la gestion } \\
\text { de programmes sociaux } \\
\text { - Oui } \\
0 \\
\text { - Non } \\
4\end{array}$ & $4(3,5)$ & $4(3,5)$ \\
\hline & & $\begin{array}{l}\text { VI) Politiques de population à } \\
\text { contenus religieux (maternité, } \\
\text { famille, soin des enfants, } \\
\text { abstinence, fidélité?) } \\
\text { - Oui } \\
0 \\
\text { - Non } \\
4\end{array}$ & $4(3,5)$ & $4(3,5)$ \\
\hline & f) Religion & $\begin{array}{l}\text { I) Utilisation des fonds publics et } \\
\text { promotion de fêtes et de pratiques } \\
\text { religieuses institutionnalisées } \\
\text { - Oui } \\
0 \\
\text { - Non } \\
4\end{array}$ & $4(3,85)$ & $0(0)$ \\
\hline & & $\begin{array}{l}\text { II) Participation officielle de hauts } \\
\text { fonctionnaires à des cérémonies } \\
\text { religieuses de culte public } \\
\text { (Te Deum, autres) } \\
\text { - Oui } \\
0 \\
\text { - Non } \\
4\end{array}$ & $4(3,85)$ & $0(0)$ \\
\hline & & $\begin{array}{l}\text { III) Lieux et symboles religieux dans } \\
\text { les institutions publiques (pouvoir } \\
\text { exécutif, législatif, judiciaire, ne pas } \\
\text { évaluer les institutions éducatives) } \\
\text { - Oui } \\
0 \\
\text { - Non } \\
4\end{array}$ & $4(2,98)$ & $0(0)$ \\
\hline & & $\begin{array}{l}\text { IV) Invocation religieuse au } \\
\text { moment de prêter serment pour les } \\
\text { postes publics ou les témoignages } \\
\text { judiciaires } \\
\text { - Oui, obligatoirement } \\
0 \\
\text { - Oui, entre autres options non } \\
\text { religieuses } \\
1 \\
- \text { Non } \\
4\end{array}$ & $4(2,98)$ & $2(1,49)$ \\
\hline
\end{tabular}




\begin{tabular}{|c|c|c|c|c|}
\hline \multicolumn{5}{|l|}{ Laïcité } \\
\hline \multirow[t]{7}{*}{ Dimension } & Sous-dimension & Indicateurs & Mexique & Argentine \\
\hline & & $\begin{array}{l}\text { V) Argumentation religieuse dans } \\
\text { les décisions de la Cour Suprême } \\
\text { - Oui } \\
0 \\
\text { - Non } \\
4\end{array}$ & $4(3,85)$ & $4(3,85)$ \\
\hline & $\begin{array}{l}\text { g) Sciences } \\
\text { et arts }\end{array}$ & $\begin{array}{l}\text { I) Liberté de chaire, de recherche et } \\
\text { de divulgation } \\
- \text { Non } \\
0 \\
- \text { Oui } \\
4\end{array}$ & $4(8,75)$ & $4(8,75)$ \\
\hline & & $\begin{array}{l}\text { II) Censure des œuvres artistiques et } \\
\text { de la production culturelle } \\
\text { - Oui } \\
0 \\
- \text { Non } \\
4\end{array}$ & & \\
\hline & $\begin{array}{l}\text { h) } \\
\text { Communication }\end{array}$ & $\begin{array}{l}\text { I) Censure des médias pour motifs } \\
\text { religieux } \\
- \text { Oui } \\
0 \\
- \text { Non } \\
4\end{array}$ & $4(525)$ & $4(525)$ \\
\hline & & $\begin{array}{l}\text { II) Programmes doctrinaires reli- } \\
\text { gieux dans les médias publics } \\
\text { - Oui } \\
0 \\
\text { - Non } \\
4\end{array}$ & $4(7)$ & $0(0)$ \\
\hline & & $\begin{array}{l}\text { III) Interdiction de manifestation } \\
\text { religieuse dans les médias } \\
\text { - Oui } \\
0 \\
- \text { En situation exceptionnelle } \\
2 \\
- \text { Non } \\
4\end{array}$ & $2(2,63)$ & $4(5,25)$ \\
\hline $\begin{array}{l}\text { Total Politiques } \\
\text { publiques }\end{array}$ & $\begin{array}{l}146 \\
(117,13)\end{array}$ & $\begin{array}{l}124 \\
(100,61)\end{array}$ & & \\
\hline
\end{tabular}


Tableau 6: culture politique au Mexique et en Argentine

\begin{tabular}{|c|c|c|c|}
\hline \multicolumn{4}{|l|}{ Laïcité } \\
\hline Dimension & Indicateurs & Mexique & Argentine \\
\hline \multirow[t]{7}{*}{$\begin{array}{l}\text { Culture } \\
\text { Politique }\end{array}$} & $\begin{array}{l}\text { I) Promotion de l'identité nationale à travers des } \\
\text { symboles religieux } \\
- \text { Oui } \\
0 \\
- \text { Non } \\
4\end{array}$ & $4(3,9)$ & $0(0)$ \\
\hline & $\begin{array}{l}\text { II) Participation d'agents religieux à l'inauguration } \\
\text { de travaux publics } \\
- \text { Oui } \\
0 \\
- \text { Parfois } \\
2 \\
- \text { Non } \\
4\end{array}$ & $4(7,8)$ & $0(0)$ \\
\hline & $\begin{array}{l}\text { III) Ingérence participative d'institutions ou d'agents } \\
\text { religieux dans les processus électoraux } \\
\text { - Directement } \\
0 \\
- \text { Indirectement } \\
1 \\
- \text { Non } \\
4\end{array}$ & $4(11,7)$ & $4(11,7)$ \\
\hline & $\begin{array}{l}\text { IV) Jurisprudence tendant à respecter les cultures } \\
\text { particulières dans le pays (multiculturalisme, } \\
\text { accommodements raisonnables) } \\
\text { - Non } \\
0 \\
- \text { Oui } \\
4\end{array}$ & $4(3,9)$ & $4(3,9)$ \\
\hline & $\begin{array}{l}\text { V) Politiques publiques tendant à la sacralisation } \\
\text { de symboles civiques } \\
\text { - Oui } \\
0 \\
- \text { Non } \\
4\end{array}$ & $0(0)$ & $0(0)$ \\
\hline & $\begin{array}{l}\text { VI) Réunions entre hauts fonctionnaires et leaders } \\
\text { religieux pour l'élaboration ou l'application } \\
\text { de politiques publiques } \\
- \text { Oui } \\
0 \\
\text { - Non } \\
4\end{array}$ & $4(11,7)$ & $0(0)$ \\
\hline & $\begin{array}{l}\text { VII) Rencontres entre candidats électoraux et } \\
\text { responsables religieux } \\
\text { - Oui } \\
0 \\
- \text { Non } \\
4\end{array}$ & $0(0)$ & $0(0)$ \\
\hline
\end{tabular}




\begin{tabular}{|c|c|c|c|}
\hline \multicolumn{4}{|l|}{ Laïcité } \\
\hline \multirow[t]{5}{*}{ Dimension } & Indicateurs & Mexique & Argentine \\
\hline & $\begin{array}{l}\text { VIII) Invocation des symboles et références } \\
\text { religieuses pour motif de prosélytisme dans les } \\
\text { discours politiques } \\
\text { - Oui } \\
0 \\
- \text { Non } \\
4\end{array}$ & $4(3,9)$ & $0(0)$ \\
\hline & $\begin{array}{l}\text { IX) Affichage de la part de l'État de symboles/ } \\
\text { espaces religieux dans les lieux publics non } \\
\text { gouvernementaux (aéroports, hôpitaux, places) } \\
\text { - Oui, mais d'un seul culte } \\
0 \\
\text { - Espace interreligieux } \\
2 \\
\text { - Non } \\
4\end{array}$ & $2(3,9)$ & $0(0)$ \\
\hline & $\begin{array}{l}\text { X) Assistance religieuse dans les lieux de réclusion } \\
\text { I: forces armées } \\
\text { - Non ou Oui, dans les espaces définis par une seule } \\
\text { religion } \\
0 \\
- \text { Permise, de fait pour une seule religion } \\
1 \\
- \text { Pour toutes les religions de fait } \\
2 \\
- \text { Garantie juridique pour toutes les religions } \\
3 \\
- \text { À la demande de la personne } \\
4\end{array}$ & $4(3,9)$ & $0(0)$ \\
\hline & $\begin{array}{l}\text { XI) Assistance religieuse dans les lieux de réclusion } \\
\text { II: unités pénitentiaires } \\
\text { - Non ou Oui, dans les espaces définis par une seule } \\
\text { religion } \\
0 \\
\text { - Permise, de fait pour une seule religion } \\
1 \\
- \text { Pour toutes les religions de fait } \\
2 \\
- \text { Garantie juridique pour toutes les religions } \\
3 \\
\text { - À la demande de la personne } \\
4\end{array}$ & $2(1,95)$ & $2(1,95)$ \\
\hline
\end{tabular}




\begin{tabular}{|c|c|c|c|}
\hline \multicolumn{4}{|l|}{ Laïcité } \\
\hline Dimension & Indicateurs & Mexique & Argentine \\
\hline & $\begin{array}{l}\text { XII) Assistance religieuse dans les lieux } \\
\text { d'isolement: hôpitaux } \\
\text { - Non ou Oui, dans les espaces définis par une seule } \\
\text { religion } \\
0 \\
- \text { Permise, de fait pour une seule religion } \\
1 \\
\text { - Pour toutes les religions de fait } \\
2 \\
\text { - Garantie juridique pour toutes les religions } \\
3 \\
- \text { À la demande de la personne } \\
4\end{array}$ & $4(3,9)$ & $0(0)$ \\
\hline & $\begin{array}{l}\text { XIII) Utilisation des fonds publics pour les } \\
\text { «traditions» ou manifestations religieuses } \\
\text { populaires non institutionnelles } \\
\text { - Oui } \\
0 \\
\text { - Non } \\
4\end{array}$ & $0(0)$ & $0(0)$ \\
\hline & $\begin{array}{l}\text { XIV) Promotion gouvernementale d'une culture } \\
\text { de la pluralité et de la diversité dans les médias } \\
\text { - Non } \\
0 \\
\text { - Oui } \\
4\end{array}$ & $4(3,9)$ & $4(3)$, \\
\hline $\begin{array}{l}\text { Total Culture } \\
\text { Politique }\end{array}$ & $40(60,45)$ & $14(21,45)$ & \\
\hline
\end{tabular}

Élaboré par les auteurs, 2014

\section{Tableau 7: Synthèse de la laïcité au Mexique et en Argentine}

\begin{tabular}{l|c:c}
\hline \multicolumn{1}{c|}{ Laïcité } & Mexique & Argentine \\
\hline Normativité juridique & $69(77,98)$ & $53(55,68)$ \\
Politiques publiques & $146(117,13)$ & $124(100,61)$ \\
Culture politique & $40(60,45)$ & $14(21,45)$ \\
\hline Total Général & $255(255,56)$ & $191(177,74)$ \\
\hline
\end{tabular}

Les différents plans d'analyse formulés nous donnent non seulement une base empirique indispensable pour analyser les niveaux de correspondance ou de déphasage entre la législation, les politiques publiques et la culture politique hégémonique, mais ils nous fournissent également des éléments de plus grande envergure pour approfondir théoriquement les processus 
d'imbrication entre le politique et le religieux, et repenser les cadres conceptuels qui existent sur la laïcité.

L'application des indicateurs aux cas du Mexique et de l'Argentine nous offrent des conclusions significatives sur les formes, les niveaux et les modalités de laïcité qui caractérisent leurs États, dès lors que l'on prend en considération le tissu juridique, politique et culturel des deux pays.

L'analyse montre que nous sommes face à des processus et des agencements complexes, dans lesquels il n'y a pas toujours de continuité entre deux dimensions analytiques au sein d'une même formation politique et géographique: les processus de laïcisation impulsés par certaines politiques publiques au Mexique ne sont pas homologables à toutes les initiatives gouvernementales concernant d'autres domaines de la vie sociale. Si l'on observe le cas de l'Argentine, des normes qui relèvent des principes de la laïcité coexistent avec une culture politique marquée par une forte empreinte religieuse.

En termes comparatifs, la configuration juridique inscrite dans la constitution et les législations qui sont au fondement de la légitimité de l'État mexicain reflète un cadre laïque qui déterminera l'autonomie et la souveraineté de l'État face aux institutions religieuses. En Argentine, la présence historique du catholicisme dans les milieux politiques se retrouve dans sa structure normative: l'invocation des valeurs confessionnelles et l'interpellation de l'Église catholique comme une institution de caractère public obligent l'État à soutenir le culte catholique apostolique romain. Or l'empreinte religieuse du juridique ne restreint à aucun moment la garantie des droits fondamentaux qui jouit, à cet égard, de la même reconnaissance qu'au Mexique.

L'inventaire des politiques publiques nous a orientés sur des lois spécifiques et sur les programmes gouvernementaux. Cette dimension est peut-être la plus dynamique et, en tant que telle, perméable aux aléas du profil politique des gouvernements à chaque période historique. C'est là que le Mexique et l'Argentine se rapprochent le plus, tout en conservant des spécificités qu'il est important de mentionner.

Dans le domaine de la bioéthique - politiques de genre et de droits sexuels et reproductifs - les deux pays font apparaître, au moins au plan intentionnel de leurs États respectifs, une reconnaissance explicite des droits civiques. Dans le cas de l'Argentine, cette reconnaissance coexiste avec la participation d'agents religieux ou non formellement religieux, mais porteurs des prescriptions axiologiques de leurs institutions confessionnelles, à divers Conseils Consultatifs ou à des Comités de Bioéthique. Dans le cas du Mexique, l'éventail des droits sexuels garantis s'oppose à l'inexistence de normes concernant l'union civile et/ou le mariage entre personnes du même sexe, même si la Cour Suprême de Justice de la Nation cherche dernièrement à faire ratifier ce droit dans tous les états fédérés. En Argentine ces normes sont garanties par la loi. Le suivi des dynamiques parlementaires et des conjonctures politiques permettront de comprendre, à partir d'autres repères, le caractère discontinu des processus ici analysés.

Sur le plan fédéral, l'avortement reste une question épineuse dans les deux pays. Si l'on prévoit une dépénalisation dans des cas spécifiques comme le viol, 
le risque de vie pour la femme et la malformation du fœetus, rien n'indique que celle-ci pourrait s'étendre à une décision souveraine de la femme. Sur le plan éducatif, le Mexique se caractérise par une forte exclusion du religieux du système public. En Argentine, malgré le mythe de l'éducation laïque, nombreux sont les interstices où le gouvernemental et le religieux sont complémentaires: financement public des institutions éducatives confessionnelles, participation des acteurs religieux aux espaces consultatifs pour l'élaboration des politiques publiques, présence des symboles religieux dans les écoles publiques, etc.

La prédominance catholique au sein du gouvernement argentin rend compte d'une inégalité religieuse. Mais il ne faut pas interpréter cette situation comme un obstacle à la garantie de multiples libertés. Il existe en Argentine une pleine liberté religieuse, liberté de chaire, de divulgation et de recherche (y compris sur les cellules mères et sur la reproduction assistée), sans constatation de censure pour des motifs religieux. Au Mexique, une certaine tradition anticléricale dans l'agir étatique a rendu ces mêmes libertés viables, raison pour laquelle les cérémonies religieuses de culte public qui ont lieu à l'extérieur des temples sont d'ordinaire bannies, y compris celles qui ont lieu dans les media électroniques (radio et télévision).

La culture politique fait apparaître des différences plus nettes entre les deux pays. Le Mexique est marqué par une idiosyncrasie prédominante de différenciation entre les espaces gouvernementaux et les espaces religieux, et les frontières qui séparent les plans politique, religieux et éducatif sont clairement définies. Par ailleurs, la culture politique se caractérise par une non-ingérence dans la vie interne des associations religieuses, elle n'intervient pas non plus sur le marché de la religion, et elle est régie par une juridictionnalisation - issue du régalisme et du patronat - de l'État souverain sur les effets sociaux des manifestations religieuses. La laïcité de la République est inscrite dans la Constitution et elle repose sur le principe de séparation de l'État et des Églises, séparation nette entre le religieux et le politique et entre l'exercice de la fonction publique et les pratiques confessionnelles privées.

Dans le cas argentin, la culture politique fait apparaître depuis fort longtemps des signes confessionnels qui favorisent l'imbrication des processus de légitimation mutuelle entre le politique et le religieux, et qui alimentent également les instances de socialisation religieuse de la direction politique. D'où l'invocation des symboles religieux dans les discours politiques, les rencontres avec les responsables religieux en période préélectorale ou la participation des religieux à l'inauguration des travaux publics. Le tableau suivant synthétise en pourcentages les niveaux de laïcité relevés dans les deux pays: 
Tableau 8 : Niveaux de laïcité au Mexique et en Argentine

\begin{tabular}{l|c|c|c|c}
\hline \multirow{2}{*}{\multicolumn{1}{c}{ Laïcité }} & \multicolumn{2}{c}{ Mexique } & \multicolumn{2}{c}{ Argentine } \\
\cline { 2 - 5 } & Non pondéré & Pondéré & Non pondéré & Pondéré \\
\hline Normativité juridique & $86,3 \%$ & $83 \%$ & $66,3 \%$ & $59,2 \%$ \\
Politiques publiques & $83 \%$ & $83,7 \%$ & $70,5 \%$ & $71,9 \%$ \\
Culture politique & $71,4 \%$ & $77,5 \%$ & $25 \%$ & $27,5 \%$ \\
\hline Total Général & $81,7 \%$ & $81,9 \%$ & $61,2 \%$ & $57 \%$ \\
\hline
\end{tabular}

Si l'on considère l'ensemble des indicateurs, l'évaluation de l'État mexicain fait apparaître un parcours plus uniforme. En Argentine, les espaces d'autonomie gouvernementale et une reconnaissance accrue de divers droits citoyens côtoient un cadre extrêmement normatif et surtout, une culture politique qui renvoie à un noyau catholique fort, à l'origine même de l'histoire de l'État argentin. Au lieu de les considérer comme des contradictions, il est intéressant d'analyser les tensions et distensions générées par les processus de négociation entre un ensemble de normes, leur traduction dans des politiques publiques et une culture politique ancrée dans les cadres administratifs chargés d'appliquer ces politiques. Que le phénomène soit dû à la culture politique dans laquelle bon nombre des décideurs gouvernementaux ont été socialisés, ou que ceux-ci soient persuadés, bien au-delà du politique, qu'ils sauront tirer profit des liens qu'ils entretiennent avec les ecclésiastiques, ces processus paraissent constitutifs de la laïcité argentine.

Ceux-ci sont loin d'être méconnus au Mexique. Les gouvernants recherchent des formes de légitimités extra-politiques, donc religieuses. Mais face aux dénonciations formulées dans l'opinion publique, ils sont obligés de faire marche arrière, ce qui témoigne d'une culture politique laïque.

Produit des tensions émergentes entre structures, groupes, acteurs religieux et non religieux qui se battent pour modifier les normes, influencer les politiques publiques, préserver un cadre axiologique, la variabilité est une composante qu'on ne peut ignorer. Si l'on prend en compte les brèches qui se creusent entre les normes et les politiques publiques, il est fondamental d'observer la dynamique des conjonctures politiques et les traditions des cultures politiques pour évaluer le poids relatif des principes de la laïcité dans chaque contexte particulier.

$$
* *
$$

Faire l'effort de comparer les laïcités mexicaine et argentine, au-delà de leurs résultats spécifiques, suscite de nombreuses interrogations quant à notre propre champ d'étude, aux manières différentes d'appréhender la laïcité et aux outils que nous utilisons pour l'observer et éventuellement la mesurer. La première d'entre elles est la suivante: est-il possible de construire un 
indice universel de laïcité ? Si nous y répondons de manière affirmative, il nous faut nuancer. Il est clair, par exemple, que les expériences historiques de l'Argentine et du Mexique sont en principe voisines: elles partagent un même héritage colonial, une tradition catholique prédominante et des développements historiques similaires. Or si les trajectoires nationales après l'indépendance de l'Espagne se ressemblent au plan économique et social, leurs processus culturels et politiques sont divergents. Le problème n'est pas géographique, mais culturel, lié à des trajectoires nationales particulières. Nous pourrions faire la même affirmation pour deux pays voisins, très proches ethniquement et socialement comme le sont l'Argentine et l'Uruguay, par exemple, mais dont les régimes en matière de laïcité et de catholicisme sont presque opposés. Le même phénomène se retrouve à plus forte raison pour deux sociétés différentes culturellement (la migration) et ethniquement (la majorité de la population argentine est blanche, tandis que la population mexicaine est métissée), et qui ont connu des développements politiques divergents. La victoire de la révolution mexicaine en 1910 a consolidé le libéralisme et l'anticléricalisme, tandis que l'Argentine a connu à partir de la décennie des années trente du Xx un processus de militarisation et de «catholicisation» accru, qui a fortement marqué la culture politique postérieure.

Mesurer la laïcité des États de ces sociétés interroge donc d'emblée l'outil utilisé: les indicateurs sont-ils adéquats et exhaustifs ou reflètent-ils une vision de ce que devrait être la laïcité ? L'approche des phénomènes politiques est-elle flexible, ou ces indicateurs sont-ils le produit d'une certaine rigidité conceptuelle?

Nous en avons longuement discuté lorsque nous nous sommes rendus compte que certains cas remettaient en cause la généralité de notre projet, ou lorsque nous avons craint de voir s'imposer une perspective plus locale, et donc non généralisable. Si notre approche est possible en matière de normativité juridique et de politiques publiques (dans lesquelles on retrouve une certaine uniformité culturelle), elle devient plus complexe en matière de culture politique. Ainsi, la participation des agents religieux à l'inauguration des travaux publics et à la définition des politiques publiques, ou l'invocation de symboles ou de références religieuses dans les discours politiques peuvent paraître anodins dans un cas, tandis que dans l'autre ces actions sont jugées sévèrement, voire punies par la loi. De même, il existe toujours une certaine indéfinition de diverses pratiques au départ religieuses, mais qui sont devenues avec le temps des traditions presque séculières, plus liées au marché (Noël) ou à des coutumes folkloriques et identitaires (la Toussaint, «le jour des morts ", au Mexique). La question fait problème lorsqu'il s'agit de l'utilisation des fonds publics pour ces "traditions" populaires, au sein des écoles ou des édifices publics. Quelle différence y a-t-il entre le financement public d'une tradition populaire religieuse, proche du culte des ancêtres mais transformé en événement folklorique sans lien particulier avec une Église, et le financement d'un rituel ou d'une cérémonie propres à une religion établie? Nous avons cherché à différencier ces pratiques et à assumer que le financement d'une 
«tradition folklorique» ne constitue pas toujours une infraction au principe de laïcité de l'État, à moins qu'il ne soutienne ouvertement une tradition particulière, comme peuvent l'être la reproduction de crèches de Noël ou la représentation d'images liées à une religion. L'évaluation de ces phénomènes est effectuée, rappelons-le, non seulement en fonction du principe de l'autonomie de l'État face à toute doctrine religieuse, mais également en fonction d'un critère d'équité. Il est donc important de vérifier si le financement public des «traditions culturelles» ou des «coutumes populaires ou traditionnelles » masque un appui financier à une religion majoritaire ou hégémonique, sous prétexte de «normalité », s'agissant d'une croyance religieuse identifiée à la culture ou à l'identité nationale. Ce que cette évaluation nous montre bien, c'est qu'il n'existe dans le monde aucun gouvernement complètement aseptique en matière religieuse.

Enfin, le fait que notre outil d'évaluation se situe au niveau national présente une difficulté supplémentaire. Il passe outre une infinité de variations régionales et locales, les différentes formes de gouvernement, les multiples cultures politiques qui coexistent à des moments historiques divers et sous des modalités différentes.

Si nous nous heurtons à ce type de difficultés dans deux sociétés au départ aussi proches que l'argentine et la mexicaine, il est clair que notre outil affrontera des difficultés d'autant plus grandes, qu'il sera appliqué à des sociétés non occidentales comme la Turquie islamique ou le Japon Shintoïste Bouddhiste, régis par d'autres religions prédominantes. Est-ce que nous mesurons bien ce que nous voulons mesurer? Notre outil n'est-il pas exclusivement le reflet des relations entre un État séculier et le monde chrétien? Ou bien s'agit-il seulement d'adapter la séquence d'indicateurs à différentes cultures afin que l'outil soit mieux compris et que l'on puisse y répondre de manière plus précise? L'exercice auquel nous nous sommes livrés nous permet d'affirmer que l'outil d'évaluation est non seulement adaptable, mais qu'il est également modifiable en fonction des réalités locales. Mais s'il veut conserver sa capacité comparative, il faut que les adaptations se réduisent au minimum indispensable, sous peine de mesurer des phénomènes différents. De toutes manières, l'outil devra être repensé lors de chaque exercice de mesure.

Roberto BLANCARTE PIMENTEL El Colegio de México blancart@colmex.mx

Juan Cruz ESQUIVEL Conicet-UBA paternal2000@gmail.com 


\section{Bibliographie}

Baubérot Jean, 2005 [2000], Historia de la laicidad francesa, México DF, El Colegio Mexiquense.

-, 2007, Les laïcités dans le monde, Paris, Presses universitaires de France.

-, Milot Micheline, 2011, Laïcités sans frontières, Paris, Éditions du Seuil.

Berger Peter, 1999, The Desecularization of the world, Washington DC, Ethics and Public Policy Center.

Blancarte Roberto, 2000, Laicidad y valores en un Estado democrático, México DF,

El Colegio de México.

-, 2008, Los retos de la laicidad y la secularización en el mundo contemporáneo, México

DF, El Colegio de México.

-, 2012, “¿Cómo podemos medir la laicidad ?”, Estudios Sociológicos, vol. XXX, n 88.

Casanova José, 1994, Public Religions in the Modern Word. Chicago, University of

Chicago Press.

-, 2009, "Religion, Politics and Gender Equity: Public Religion Revisited”, José Casanova,

Anne Phillips (contributors), A Debate on the Public Role of Religion and its Social and Gender Implications, Gender and Development Paper, $n^{\circ}$ 5, UNRISD, Heinrich Boll Stiftung.

DA Costa Néstor (org.), 2006, Laicidad en América Latina y Europa, Montevideo, CLAEH. Esquivel Juan Cruz, 2004, Detrás de los muros. La Iglesia católica en tiempos de Alfonsín y Menem (1983-1999), Bernal, Editorial de la Universidad de Quilmes.

-, 2009, “Cultura política y poder eclesiástico: Encrucijadas para la construcción del Estado laico en Argentina”, Paris, Archives des sciences sociales des religions, $\mathrm{n}^{\circ} 146$. -, 2010, "Notas sobre la laicidad en Argentina”, Revista Debates do Núcleo de Estudos da Religião, no 18, Año II, Programa de Pós-Graduação em Antropología Social da Universidade Federal do Río Grande do Sul.

Mallimaci Fortunato, 2008, "Nacionalismo católico y cultura laica en Argentina”, Blancarte R. (coord.), Los retos de la laicidad y la secularización en el mundo contemporáneo, México DF, El Colegio de México.

Minot Micheline, 2009, La laicidad, Madrid, Editorial CCS.

Poulat Émile, 2012 [2003], Nuestra laicidad pública, México, Fondo de Cultura Económica.

Weber Max, 1984, Ensayos sobre sociología de la religión, Madrid, Taurus.

ZanatTa Loris, 1996, Del Estado liberal a la Nación católica. Iglesia y ejército en los orígenes del peronismo (1930-1943, Bernal, Universidad Nacio

\section{Indicateurs de laïcité dans les démocraties contemporaines: analyse comparative entre le Mexique et l'Argentine}

Nous ne pouvons pas réduire les alternatives réelles de la plupart des sociétés contemporaines aux seules deux catégories d'État confessionnel et d'État laïc ou séculier. Le problème n'est plus de savoir quels sont les pays laïques et ceux qui ne le sont pas, mais plutôt de comprendre dans quelle mesure et jusqu'à quel point un pays est lä̈que. Nous nous proposons ici de mettre à 
l'épreuve un outil méthodologique qui offre une série d'indicateurs de laïcité, afin de parvenir non seulement à identifier des niveaux de lä̈cisation étatique, mais également le profil adopté par la lä̈cité dans chaque pays. Cet outil prétend analyser la laïcité dans différents contextes politiques et culturels. La comparaison porte sur le Mexique et l'Argentine, deux pays d'une même aire culturelle qui ont pourtant emprunté des voies différentes quant aux rapports entre politique et religion.

Mots-Clés: laïcité, État, sécularité, Mexique, Argentine.

\section{Indicators of secularism in contemporary democracies: a comparative analysis between Mexico and Argentina}

We should not reduce the real alternatives of most contemporary societies only to the categories of Confessional State and Secular (Lay) State. The question is not about which countries are secular and which are not, but to understand to what extent a country is secular. In this article we propose to test a methodological instrument that offers a series of "laicity" (secularity) indicators with the intention of identifying not only the levels of secularization of each State, but also the particular profile adopted by secularity/laicity in every country. This instrument pretends to analyze the "laïcity" or secularity in different political and cultural contexts. A comparison made between Argentina and Mexico, two countries of a similar cultural background, which have nevertheless taken different paths concerning relations between politics and religion.

Key words: laicity, state, secularity, Mexico, Argentina.

\section{Indicadores de la laicidad en las democracias contemporáneas: análisis comparativo entre México y Argentina}

No podemos reducir las alternativas reales de la mayor parte de las sociedades contemporáneas únicamente a las categorías de Estado confesional y Estado laico o secular. El problema no es el de saber cuáles son los países laicos y cuáles no lo son, sino de comprender en qué medida y hasta qué punto un país es laico o secular. Aqui nos proponemos poner a prueba un instrumento metodológico que ofrece una serie de indicadores de laicidad, con el objeto de identificar no solamente los niveles de laicización del Estado, sino también el perfil adoptado por la laicidad en cada país. Este instrumento pretende analizar la laicidad en diferentes contextos politicos y culturales. La comparación se hace entre Argentina y México, dos países de una misma región cultural, que sin embargo han tomado vías diferentes en cuanto a las relaciones entre política y religión.

Palabras clave: laicidad, estado, secularidad, México, Argentina. 